\title{
Ethanolic Extract of Butea monosperma Leaves Elevate Blood Insulin Level in Type 2 Diabetic Rats, Stimulate Insulin Secretion in Isolated Rat Islets, and Enhance Hepatic Glycogen Formation
}

\author{
Mehdi Bin Samad, Ashraf Ul Kabir, Ninadh Malrina D'Costa, Farjana Akhter, Arif Ahmed, \\ Mohammad Rajib Jahan, and J. M. A. Hannan
}

Department of Pharmacy, North South University, Plot 15, Block B, Bashundhara R/A, Dhaka 1229, Bangladesh

Correspondence should be addressed to Mehdi Bin Samad; mehdi827@phr.northsouth.edu

Received 20 October 2013; Revised 6 February 2014; Accepted 25 February 2014; Published 31 March 2014

Academic Editor: Siew Hua Gan

Copyright (C) 2014 Mehdi Bin Samad et al. This is an open access article distributed under the Creative Commons Attribution License, which permits unrestricted use, distribution, and reproduction in any medium, provided the original work is properly cited.

\begin{abstract}
We measured a vast range of parameters, in an attempt to further elucidate previously claimed antihyperglycemic activity of Butea monosperma. Our study clearly negates the possibility of antidiabetic activity by inhibited gastrointestinal enzyme action or by reduced glucose absorption. Reduction of fasting and postprandial glucose level was reconfirmed $(P<0.05)$. Improved serum lipid profile via reduced low density lipoprotein (LDL), cholesterol, triglycerides (TG), and increased high density lipoprotein (HDL) was also reestablished $(P<0.05)$. Significant insulin secretagogue activity of $B$. monosperma was found in serum insulin assay of B. monosperma treated type 2 diabetic rats $(P<0.01)$. This was further ascertained by our study on insulin secretion on isolated rat islets $(P<0.05)$. Improved sensitivity of glucose was shown by the significant increase in hepatic glycogen deposition $(P<0.05)$. Hence, we concluded that antihyperglycemic activity of $B$. monosperma was mediated by enhanced insulin secretion and enhanced glycogen formation in the liver.
\end{abstract}

\section{Introduction}

Throughout the recorded history, diabetes mellitus has affected the life of millions of people of all age, sex, race, and economic status [1-4]. Studies show that, between 2009 and 2034, the number of people with diagnosed and undiagnosed diabetes will increase from 23.7 million to 44.1 million in the United States [5]. Throughout the world, diabetes mellitus is a significant reason for hospitalization, disability and in consequence imposes great financial losses to the society [6]. Epidemiologic studies and randomized clinical trials indicate that type 2 diabetes is somewhat preventable through diet and lifestyle modifications [7]. However, majority would still require taking hypoglycemic agents [8]. These agents are highly effective; however, their use is still restricted due to their high cost, adverse effects, high incidences of secondary failure, and extremely limited pharmacokinetic properties
[9]. Plants have been a source of medicinal treatments for eons, and phytotherapy continue to play an indispensible role in primary health care of about $80 \%$ of the world's underdeveloped and developing countries [10]. The trend of using complementary and alternative medicines (CAM) has increased in recent years both in the developing and developed countries [11]. Due to limited research, findings on proving safety and efficacy of CAM are scarce [12]. Hence, time demands pharmacological profiling of such drugs in order to indentify the ones that are truly effective. Antidiabetic drugs work in one of the following ways: enhancement of insulin secretion, decreased production of glucose from glycogen, increased insulin sensitivity, reduced carbohydrate absorption, and increased cell utilization of cellular glucose [9]. Our present studies elucidate the basic mechanisms of antidiabetic action of Butea monosperma. B. monosperma has been previously studied for its antidiabetic 
activity. Antihyperglycemic activity of B. monosperma has been shown in type 2 diabetic rats [13-16]. Studies have found improved serum HDL level, reduced cholesterol, and LDL levels [13-16]. Its protective role on liver and pancreas, due to its antioxidative activity has also been widely studied [1517]. Sharma and Garg have shown in vivo antioxidant effect, hypolipidemic property, and antidiabetic effect on leaves of $B$. monosperma and provide a sound foundation of this present study [18]. However, no study has been undertaken to elucidate the principal mechanism of its antihyperglycemic activity. Toxicity study (unpublished data) shows Butea monosperma to be safe up to a dose of $2000 \mathrm{mg} / \mathrm{kg}$. Our study has been systematically organized to reconfirm the above claims and study the principal mechanism in which $B$. monosperma might function. To assay the potential insulin secretagogue activity, we have employed in vivo assay of serum insulin of type 2 diabetic model rats and isolated rat Islets. Liver glycogen content was assayed, in tandem, with the above studies. Soluble dietary fibers present in certain plants known for their antidiabetic activity are capable of binding with glucose, thus retarding glucose absorption [19]. Effect of B. monosperma on glucose absorption and sucrose digestion was analyzed employing a wide array of in vitro and in situ techniques. The objective of our current study is to elucidate the pancreatic and extrapancreatic activity of $B$. monosperma.

\section{Materials and Methods}

2.1. Plant Collection and Processing. Leaf of B. monosperma was procured from Sonpara village of Narshindhi District, Bangladesh. The plant was identified by a botanist prior to further processing and a voucher specimen (specimen number: BG-234/E3) was deposited at the National Hebarium, Dhaka, Bangladesh. The leaves were cleaned off of dirt and other debris and then thoroughly washed under running tap water to reduce the microbial contamination load. They were then air dried in an oven at $40^{\circ} \mathrm{C}$ and milled into a fine powder. $100 \mathrm{gm}$ of this powder was then dissolved in $1 \mathrm{~L}$ ethanol and shaken in an orbital shaker ( $550 \mathrm{rpm}$ for $48 \mathrm{hr}$ ). The mixture was then cloth filtered to remove the coarse insoluble particles. The fine particles were forced to sediment by centrifugation ( $1500 \mathrm{rpm}$ for $10 \mathrm{~min}$ ). The supernatant was carefully pipetted out and was further filtered using a Whatman filter paper. The filtrate was then concentrated by vacuum evaporation at $75^{\circ} \mathrm{C}$ using the Soxhlet apparatus (Electrothermal Soxhlet Extractor, UK). The concentrate was left in a refrigerator for 7 days to remove ethanol further, converting it into a gummy substance. This then underwent freeze drying at $-55^{\circ} \mathrm{C}$ to obtain a fine powder. The fine powder extract was kept in Scott bottles along with silica gel sachets (desiccant) until further use.

2.2. Animal Handling. Both the healthy and type 2 diabetic rats (Long Evan type) were bred in the animal house of the Department of Pharmacy Practice, North South University, Dhaka, Bangladesh. The healthy rats weighted about 180220 gm, while the type 2 diabetic rats weighed about 160$180 \mathrm{gm}$ at the time of the experiment. All test animals were kept in the North South University animal house at an ambient temperature of $22 \pm 5^{\circ} \mathrm{C}$ and humidity of $50-70 \%$. $12 \mathrm{hr}$ day-night cycle was maintained to avoid fluctuations in the circadian rhythm. Standard rat pellets (collected from ICDDR, B) and filtered drinking water were made available to the test animals ad libitum throughout the experiment apart from the period of fasting prior to certain tests. During fasting only water was given. During most experimental period, the rats were kept in translucent plastic cages with wood shavings provided as bedding. Animals undergoing fasting were placed in grilled bottomed cages, with no bedding, to prevent coprophagy. The designed experimental protocol was evaluated and subsequently approved by the Ethics Committee on Animal Research, North South University, following the "revised guide for the care and use of laboratory animals by American Physiological Society" [20].

2.3. Diabetes Induction. Type 2 diabetes was induced in the rats by an intraperitoneal injection of streptozotocin (STZ) in citrate buffer solution at a dose of $90 \mathrm{mg} / \mathrm{kg}$. New born rats less than of $48 \mathrm{hr}$ age weighing $7 \mathrm{gm}$ were chosen for the procedure. Experiments were conducted three months after the STZ injection. The type 2 diabetic rats were selected for the experiment after conducting an oral glucose tolerance test (OGTT) and only the diabetic model rats with blood glucose levels of 8-12 mmol/L under fasting conditions were selected for the experiments as previously described [21, 22].

2.4. Chronic and Acute Effects of Ethanolic Extract of B. monosperma on Glucose Homeostasis. To evaluate effects on fasting blood glucose, the B. monosperma extract $(250 \mathrm{mg} / \mathrm{kg}$, $500 \mathrm{mg} / \mathrm{kg}$ and $1000 \mathrm{mg} / \mathrm{kg}$ ) was suspended in distilled water and orally administered to $12 \mathrm{~h}$ fasted type 2 diabetic rats. The control animals received an equal volume of distilled water.

Effects on glucose tolerance were similarly evaluated by administration of $B$. monosperma extracts together with glucose $(2.5 \mathrm{~g} / 10 \mathrm{~mL}$ per $\mathrm{kg}$ body weight $)$ after a fasting period of $12 \mathrm{~h}$. Control group received only glucose solution.

In either cases blood was collected from the tail vein, and serum separated by centrifugation and stored at $-22^{\circ} \mathrm{C}$ until further analysis. Blood glucose was analysed by GOD-PAP method [23] (glucose kit, Randox, UK).

To evaluate chronic effects of $B$. monosperma, type 2 diabetic rats were given extract at 250,500, and $1000 \mathrm{mg} / \mathrm{kg}$ doses by gavage, twice daily for $48 \mathrm{~d}$. Control rats were similarly administered water alone $(10 \mathrm{~mL} / \mathrm{kg}$ body weight). Blood samples were collected from the cut tip of the tail at the times indicated in the figures (Figure 4). Serum was separated by centrifugation, stored, and analyzed as mentioned above.

2.5. Effects of B. monosperma on Plasma Insulin. Blood was drawn from fasted type 2 diabetic rats, $1 \mathrm{hr}$ after administration of B. monosperma. The amount of insulin released from the pancreas in vivo was determined using Rat Insulin ELISA Kit (Crystal Chem, USA).

2.6. Effects of B. monosperma on Insulin Secretion from Isolated Pancreatic Islets. Pancreatic islets were isolated by 
collagenase digestion with minor modifications as previously described [24]. The amount of insulin released from the isolated islets in the presence of $3 \mathrm{mM}$ and $11 \mathrm{mM}$ glucose by $B$. monosperma extract at different doses $(20,40$, and $80 \mathrm{mg} / \mathrm{mL}$ ) was determined by Rat Insulin ELISA Kit (Crystal Chem, USA).

2.7. Effects of B. monosperma on Liver Glycogen Content. Briefly, after the 48 days of chronic administration of the extract to the type 2 diabetic rats, the liver was collected, weighed, and finely homogenized with $20 \mathrm{~mL}$ of $5 \%$ trichloroacetic acid (TCA). The proteins precipitated, which was filtered off, and the clear filtrate was analysed for glycogen. The liver glycogen content was determined following the anthrone method as described previously [25].

2.8. Effects of B. monosperma on Intestinal Glucose Absorption. An in situ intestinal perfusion technique [26] was used to determine the effect of $B$. monosperma intestinal absorption of glucose in $36 \mathrm{~h}$ fasted nondiabetic rats anaesthetized using Ketamine $(80 \mathrm{mg} / \mathrm{kg})$. Ethanol extract of B. monosperma ( $5 \mathrm{mg} / \mathrm{mL}, 10 \mathrm{mg} / \mathrm{mL}$, and $20 \mathrm{mg} / \mathrm{mL}$ equivalent to $0.25 \mathrm{~g} / \mathrm{kg}$, $0.5 \mathrm{~g} / \mathrm{kg}$, and $1 \mathrm{~g} / \mathrm{kg}$ ) was suspended in Krebs Ringer buffer, along with glucose $(54 \mathrm{~g} / \mathrm{L})$. These were passed through rat pylorus via a butterfly cannula and the perfusate collected by means of a tube inserted at the end of ileum. The control group was perfused with Krebs Ringer buffer along with glucose only. Perfusion was carried out at a rate of $0.5 \mathrm{~mL} / \mathrm{min}$ for $30 \mathrm{~min}$ at $37^{\circ} \mathrm{C}$. The results were presented as percentage of absorbed glucose, calculated from the percentage change in the amount of glucose in solution before and after the perfusion.

2.9. Effects of B. monosperma on Sucrose Absorption from the Gastrointestinal Tract. The effect of B. monosperma on sucrose absorption from gastrointestinal tract was assayed by determining the unabsorbed sucrose content following oral sucrose load by six-segment study as described by Hannan et al. [27]. $12 \mathrm{~h}$ fasted type 2 diabetic rats were administered $50 \%$ sucrose solution per oral $(2.5 \mathrm{~g} / \mathrm{kg}$ body mass $)$ along with three doses of $B$. monosperma $(250 \mathrm{mg} / \mathrm{kg}, 500 \mathrm{mg} / \mathrm{kg}$, and $1000 \mathrm{mg} / \mathrm{kg}$ ) and equal volume of water for control. Blood was sampled at the following time intervals: 30, 60, 120 , and $240 \mathrm{~min}$, after sucrose load for the quantification of blood glucose. At these time intervals, some of the rats were sacrificed for determining unabsorbed sucrose contents of the GI tract. The GI tract was excised and separated into six segments: the stomach, the upper $20 \mathrm{~cm}$, middle and lower $20 \mathrm{~cm}$ of the small intestine, the caecum, and the large intestine. Each segment was rinsed with acidified icecold saline followed by centrifugation at $3000 \mathrm{rpm}(1000 \mathrm{~g})$ for $10 \mathrm{~min}$. The supernatant was pipette out and boiled for $2 \mathrm{~h}$, in sulphuric acid, to hydrolyse the sucrose. The sulfuric acid was later neutralized by $\mathrm{NaOH}$ solution. Both plasma glucose concentration and the amount of glucose released from residual sucrose in the GI tract were determined. The GI sucrose content was calculated from the amount of liberated glucose [28].
2.10. Effects of B. monosperma on Gut Motility. Gastrointestinal motility was determined by means of $\mathrm{BaSO}_{4}$ milk following the previously described method of Chatterjee [29]. $\mathrm{BaSO}_{4}$ milk was prepared by mixing $\mathrm{BaSO}_{4}$ as $10 \%$ (w/v) in $0.5 \%$ carboxymethyl cellulose to form a suspension. The ethanol extract was administered per oral, $1 \mathrm{hr}$ before the oral administration of $\mathrm{BaSO}_{4}$ milk. Control group was administered distilled water only $(10 \mathrm{~mL} / \mathrm{kg})$. Rats belonging to all groups were sacrificed 15 min after $\mathrm{BaSO}_{4}$ administration. The distance travelled by $\mathrm{BaSO}_{4}$ milk was measured and represented as a percentage of total length of the small intestine (from pylorus to ileocaecal junction).

\subsection{Effects of B. monosperma on Intestinal Disaccharidase} Enzyme Activity. The assay was conducted following the procedure as described previously by Hannan et al. [27]. The ethanol extract of B. monosperma (250, 500, and $1000 \mathrm{mg} / \mathrm{kg}$ ) was administered by gastric gavage to $20 \mathrm{hr}$ fasted nondiabetic rats. After $60 \mathrm{~min}$, the rats were sacrificed and the small intestine was isolated, cut longitudinally, rinsed with ice-cold saline, and homogenized in $10 \mathrm{~mL}$ saline $(0.9 \% \mathrm{NaCl})$. Aliquots of homogenate were incubated with $40 \mathrm{mM}$ sucrose at $37^{\circ} \mathrm{C}$ for $60 \mathrm{~min}$. The amount of protein was determined by DC Protein Kit (Bio Rad, USA). Disaccharidase activity was determined from the glucose concentration converted from sucrose as $\mu \mathrm{mol} / \mathrm{mg}$ protein/h.

2.12. Effect of B. monosperma on Body Mass, Food, and Water Intake of Type 2 Diabetic Rats. The rats kept for chronic study were provided with sufficient amounts of food and water for one day. At the end of the day, the mass of food and volume of water intake was recorded. The change in body mass of the rats was also monitored at periods as shown in the graph (Figure 9).

2.13. Effects of B. monosperma on Organ Weight Ratio of Liver and Pancreas. The animals used on the chronic study were sacrificed by cervical dislocation at the end of the study period and the liver and pancreas were excised. They were cleaned of fats and were kept moist at all times keeping them in normal saline $(0.9 \%$ of $\mathrm{NaCl})$. The wet mass of the organs was immediately weighed using a digital balance. The weight of the pancreas was expressed as $\mathrm{mg} / 100 \mathrm{gm}$ of body weight, while the weight of the liver was represented as gm/100 gm of body weight, as shown in the graphs (Figure 10).

\subsection{Chronic Effects of Ethanolic Extracts of B. monosperma on} Serum Lipid Profile of Type 2 Diabetic Model Rats. To assess chronic effects of $B$. monosperma, type 2 diabetic model rats were treated with ethanol extract of $B$. monosperma at three dosages $(250 \mathrm{mg} / \mathrm{kg}, 500 \mathrm{mg} / \mathrm{kg}$, and $1000 \mathrm{mg} / \mathrm{kg}$ ) by gastric gavages, twice daily for $48 \mathrm{~d}$. Control rats were administered only distilled water of similar volume. Blood samples were collected from the tail vein, at times, indicated in the graphs (Figure 11). Serum was separated by centrifugation and stored at $22^{\circ} \mathrm{C}$ until further analysis. 
2.15. Effect of B. monosperma on Jejunal Nutrient Absorption by Glucose Dialysis-Tube Retardation Assay. Dry, precut dialysis sacs (inflated diam. approx. $16 \mathrm{~mm}$, length $=30 \mathrm{~cm}$, Sigma Aldrich, USA) were soaked in $1 \mathrm{~g}$ sodium azide/L. The bag was loaded with $6 \mathrm{~mL}$ sodium azide $(1 \mathrm{gm} / \mathrm{L})$ and $36 \mathrm{mg}$ glucose alone (the control sac) or after addition of fine powder of $B$. monosperma. The dry fibrous powder was wetted by an aqueous solution of sodium azide $(1 \mathrm{~g} / \mathrm{L})$ for $14 \mathrm{~h}$ prior to the experiment. The sacs were closed at the ends and hung in a solution of $100 \mathrm{~mL}$ of sodium azide $(1 \mathrm{~g} / \mathrm{L})$ and then placed in a stirred bath at $37^{\circ} \mathrm{C}$ for $1 \mathrm{hr}$. At 30 and $60 \mathrm{~min}$ time interval, $2 \mathrm{~mL}$ of the dialysate was analyzed for glucose by the GOD-PAP method following the manufacturer's instruction manual available in the website of Sigma Aldrich.

The effect of fiber on nutrient absorption was indicated by the glucose dialysis retardation index:

$$
-\frac{\text { Total glucose diffused from sac containing fiber }}{\text { Total glucose diffused from sac containing no fiber present }} \times 100 \text {. }
$$

2.16. Effect of B. monosperma on $\alpha$-Amylase Activity. The effects of $B$. monosperma powder on starch digestibility were determined as a function of time in a fiber-enzyme-starch mixture system using a dialysis membrane with a cutoff molecular weight of 12,000 da (inflated diam. approx. $16 \mathrm{~mm}$, length $=30 \mathrm{~cm}$, Sigma Aldrich, USA) as previously described with minor modifications [30]. A solution was prepared by mixing $0.2 \mathrm{~g}$ of powdered B. monosperma and $0.04 \mathrm{~g} \alpha$ amylase (obtained from human saliva, Sigma Aldrich, USA) in $10 \mathrm{~mL}$ of potato starch solution $(4 \mathrm{~g} / 100 \mathrm{~mL})$ was dialyzed in $200 \mathrm{~mL}$ deionised water at $37^{\circ} \mathrm{C}$. Following the incubation period, 10, 30, 60, and $120 \mathrm{~min}$, glucose concentration in the dialysate solution was assayed using the GOD-PAP method as described previously. The control was run without the addition of powder.

2.17. Determination of Glucose-Adsorption Capacity. The assay was conducted following the procedure by $\mathrm{Ou}$ et al. [31], where the glucose-adsorption ability ( $\mathrm{mM} / \mathrm{mol} / \mathrm{gm})$ was measured by mixing $1 \mathrm{~g}$ of insoluble plant powder or carboxymethyl cellulose (CMC) with $100 \mathrm{~mL}$ of glucose solution at a constant temperature of $37^{\circ} \mathrm{C}$ for $6 \mathrm{hr}$. This was then followed by centrifugation at $3500 \mathrm{rpm}$ for $15 \mathrm{~min}$. Glucose concentration in the supernatant was assayed using GODPAP method as previously described.

2.18. Statistical Analysis. Statistical tests were conducted using Statistical Package for Social Science Software (SPSS) ver. 20 (IBM, Inc., Chicago, IL, USA). Results are presented as means \pm SEM or mean \pm SD, whichever appropriate. Data from experimental groups were compared using unpaired Student's $t$-test and the Mann-Whitney $U$-test, as required. Experiments with data being collected at several time intervals were analyzed using repeated measures ANOVA followed by Bonferroni adjustment ensuring an error margin within $\leq 5 \%$. One-way ANOVA was carried out and pairwise comparisons were made with the control group using Dunnett's test to maintain an acceptable error margin of $5 \%$.

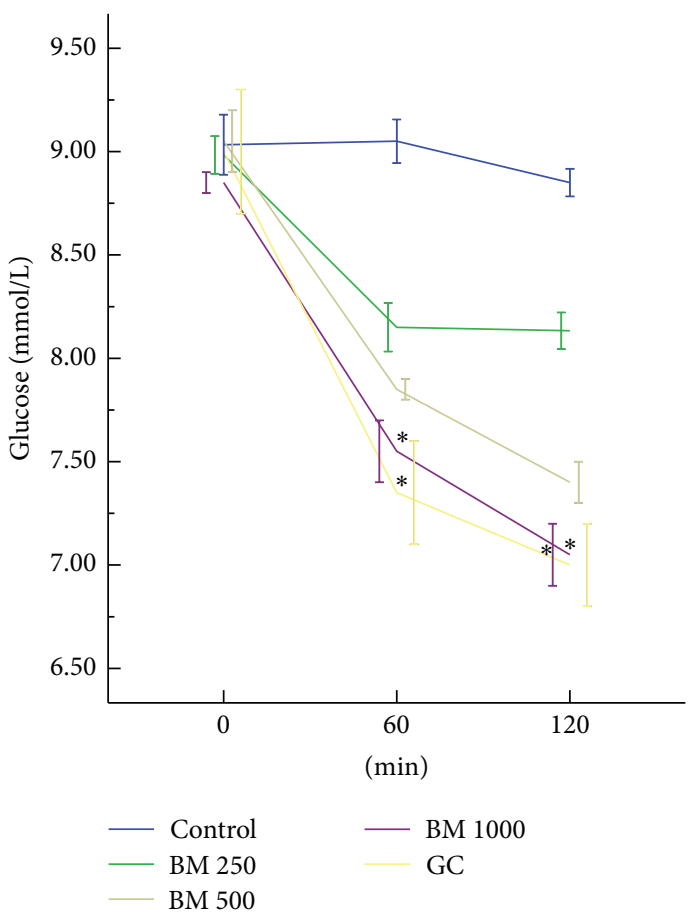

FIGURE 1: Effects of ethanol extract of Butea monosperma (BM) on fasting blood glucose (FBG) level in type 2 diabetic rats. Values are means and standard deviations represented by vertical bars $(n=10)$. Fasted rats were given ethanol extract of BM $(250 \mathrm{mg} / \mathrm{kg}, 500 \mathrm{mg} / \mathrm{kg}$, and $1000 \mathrm{mg} / \mathrm{kg}$ body weight) or Glibenclamide (GC) $(0.5 \mathrm{mg} / \mathrm{Kg})$ by oral administration. Mean values marked with an asterisk $(*)$ were significantly different from those of respective control rats $(P<$ 0.05 ) (derived from repeated measures ANOVA and adjusted using Bonferroni correction).

A two-tailed $P$ value of $<0.05$ was considered statistically significant.

\section{Results}

3.1. Acute and Chronic Effects of B. monosperma on Glucose Homeostasis. Oral administration of B. monosperma, in a dose-dependent manner, changed the antihyperglycemic condition of fasted type 2 diabetic rats; however, only the effect of $1000 \mathrm{mg} / \mathrm{kg}$ dose was significant $(P<0.05)$ (Figure 1). The extract, at $500 \mathrm{mg} / \mathrm{Kg}$ and $1000 \mathrm{mg} / \mathrm{Kg}$ doses, improved glucose homeostasis both at $60 \mathrm{~min}$ and $120 \mathrm{~min}$, when administered along with glucose load $(P<0.05$; Figure 2). The extract also increased the level of plasma insulin significantly at $1000 \mathrm{mg} / \mathrm{Kg}$ dose $(P<0.01$; Figure 3$)$.

After a 48 days chronic study of $B$. monosperma (three doses, administered twice daily) on type 2 diabetic rats, both $500 \mathrm{mg} / \mathrm{Kg}$ and $1000 \mathrm{mg} / \mathrm{Kg}$ doses showed significant reduction in serum glucose level $(P<0.05$; Figure 4).

3.2. Effect of B. monosperma on Serum Glucose after Sucrose Load. Only the $1000 \mathrm{mg} / \mathrm{Kg}$ dose of B. monosperma showed 


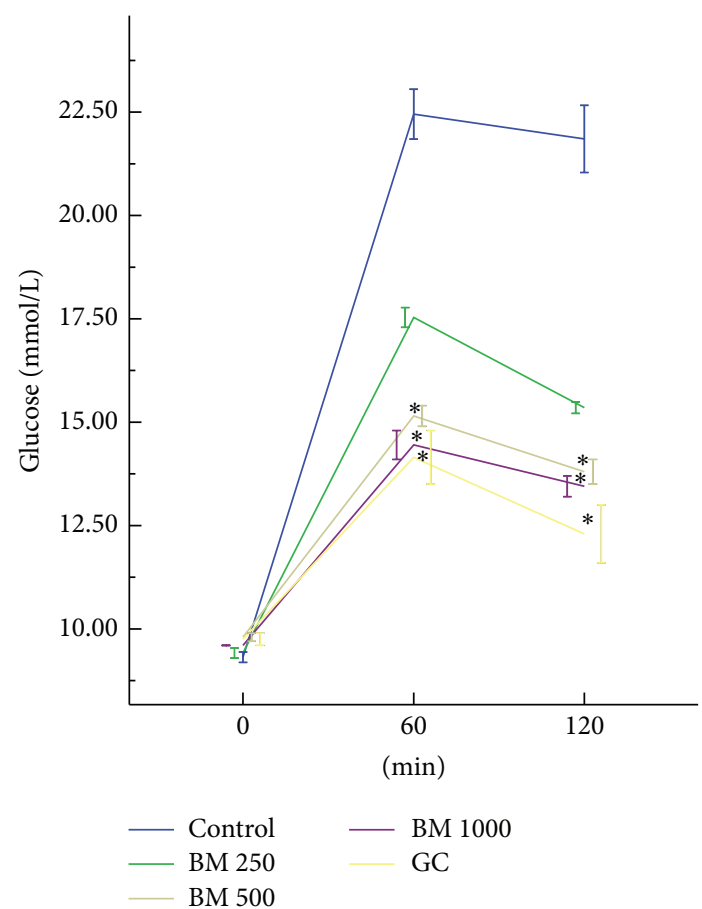

Figure 2: Effects of ethanol extract of Butea monosperma (BM) on oral glucose tolerance test (OGTT) in type 2 diabetic rats. Values are means and standard deviations represented by vertical bars $(n=11)$. Fasted rats were given ethanol extract of BM $(250 \mathrm{mg} / \mathrm{kg}, 500 \mathrm{mg} / \mathrm{kg}$, and $1000 \mathrm{mg} / \mathrm{kg}$ body weight) or Glibenclamide (GC) $(0.5 \mathrm{mg} / \mathrm{Kg})$ by oral administration with glucose $(2.5 \mathrm{~g} / \mathrm{kg}$ body weight). Mean values marked with an asterisk $(*)$ were significantly different from those of respective control rats $(P<0.05)$ (derived from repeated measures ANOVA and adjusted using Bonferroni correction).

a significant $(P<0.05)$ suppression of serum glucose level at $60 \mathrm{~min}$ and $120 \mathrm{~min}$ compared to control, where a quick peak serum glucose was observed after administration of sucrose load (Figure 5).

\subsection{Effect of B. monosperma on Intestinal Glucose Absorption.} $B$. monosperma extract, when was perfused with glucose, failed to show any significant reduction in the extent of glucose absorption during the perfusion period (Figure 6).

\subsection{Effect of B. monosperma on Unabsorbed Sucrose Content} in the Gastrointestinal Tract. Upon oral administration of sucrose along with $B$. monosperma $(1000 \mathrm{mg} / \mathrm{Kg})$, there was no significant amount of unabsorbed sucrose present in the stomach, upper, middle, lower intestine, caecum, and large intestine (Figure 7).

\subsection{Effect of B. monosperma on Gut Motility and Intestinal} Disaccharidase Enzyme Activity. None of the doses of $B$. monosperma extract altered the gastrointestinal motility. The extract also failed to show any significant inhibition of disaccharidase enzyme activity (Figure 8).

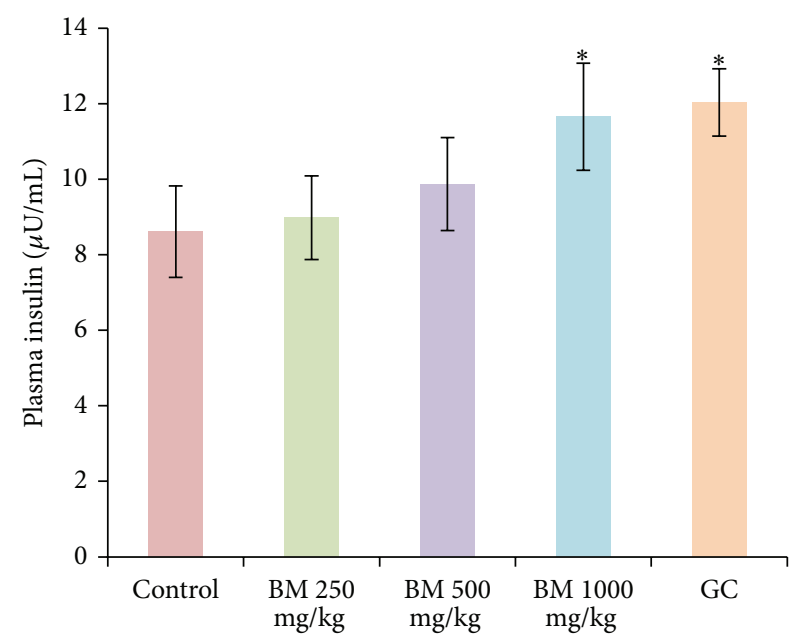

FIGURE 3: Effects of ethanol extract of Butea monosperma (BM) on serum insulin level in fasted type 2 diabetic rats. Values are means and standard deviations represented by vertical bars $(n=8)$. Rats were given ethanol extract of BM $(250 \mathrm{mg} / \mathrm{kg}, 500 \mathrm{mg} / \mathrm{kg}$, and $1000 \mathrm{mg} / \mathrm{kg}$ body weight) or Glibenclamide (GC) $(0.5 \mathrm{mg} / \mathrm{Kg})$ by oral administration. Mean values marked with an asterisk $(*)$ were significantly different from those of respective control rats $(P<$ 0.01 ) (derived from repeated measures ANOVA and adjusted using Bonferroni correction).

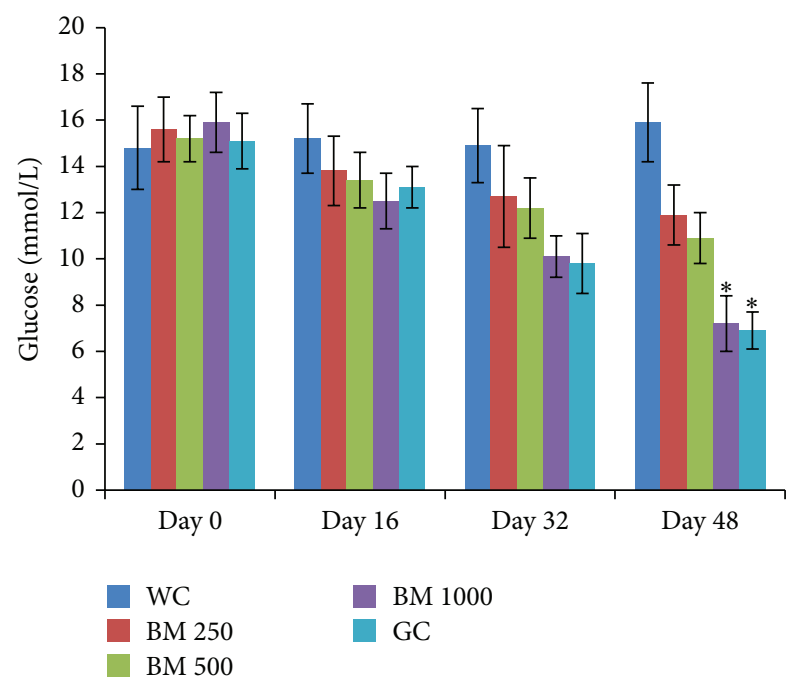

Figure 4: Effects of ethanol extract of Butea monosperma (BM) on fasting serum glucose level in type 2 diabetic rats after 48 days of feeding. Values are means and standard deviations represented by vertical bars $(n=10)$. Fasted rats were given ethanol extract of BM $(250 \mathrm{mg} / \mathrm{kg}, 500 \mathrm{mg} / \mathrm{kg}$, and $1000 \mathrm{mg} / \mathrm{kg}$ body weight) or Glibenclamide (GC) $(0.5 \mathrm{mg} / \mathrm{Kg})$ by oral administration for a period of 48 days. Mean values marked with an asterisk $(*)$ were significantly different from those of respective control rats (Water control, WC) $(P<0.05)$ (derived from repeated measures ANOVA and adjusted using Bonferroni correction). 


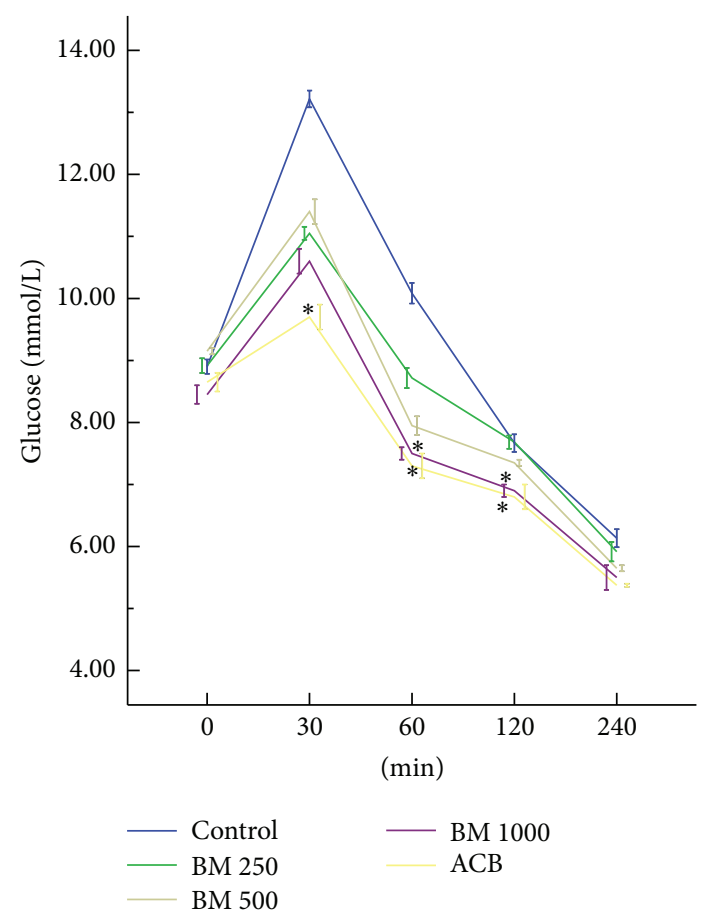

FIGURE 5: Effects of ethanol extract of Butea monosperma (BM) on serum glucose after the sucrose load in type 2 diabetic rats. Rats were fasted for $20 \mathrm{~h}$ and administered orally with a sucrose solution $(2.5 \mathrm{~g} / \mathrm{kg}$ body weight) with or without ethanol extract of $\mathrm{BM}$ $(250 \mathrm{mg} / \mathrm{kg}, 500 \mathrm{mg} / \mathrm{kg}$, and $1000 \mathrm{mg} / \mathrm{kg}$ body weight) or Acarbose (ACB) $(200 \mathrm{mg} / \mathrm{Kg})$. Values are means and standard deviations represented by vertical bars $(n=8)$. Mean values marked with an asterisk $(*)$ were significantly different from those of respective control rats $(P<0.05)$ (derived from repeated measures ANOVA and adjusted using Bonferroni correction).

3.6. Effect of B. monosperma on Insulin Secretion from Isolated Rat Islets. B. monosperma extract, at $80 \mu \mathrm{g} / \mathrm{mL}$ dose, stimulated insulin secretion significantly from the isolated rat islets in the presence of both $3 \mathrm{mM}$ and $11 \mathrm{mM}$ glucose (Table 1).

3.7. Chronic Effect of B. monosperma on Liver Glycogen, Organ Weight, Food Habit, and Serum Lipid Profile. After the 48 days long study of $B$. monosperma (three doses: 250, 500 , and $1000 \mathrm{mg} / \mathrm{Kg}$, administered twice daily) on type 2 diabetic rats, significant reduction in food intake, and water intake was observed $(P<0.05$; Figure 9). However, no significant change was seen in overall body weight. The chronic treatment of the extract also significantly increased liver glycogen content and pancreas weight; however, no change in liver weight was observed $(P<0.05$; Figure 10).

$1000 \mathrm{mg} / \mathrm{Kg}$ dose of $B$. monosperma extract improved serum lipid profile of type 2 diabetic rats after 48 days of twice daily oral feeding. It decreased the level of serum triglyceride, low density lipoprotein (LDL), and cholesterol significantly, which was comparable to the effect of reference drug Glibenclamide. Moreover, the extract increased the level of high density lipoprotein (HDL) significantly $(P<0.05$; Figure 11).

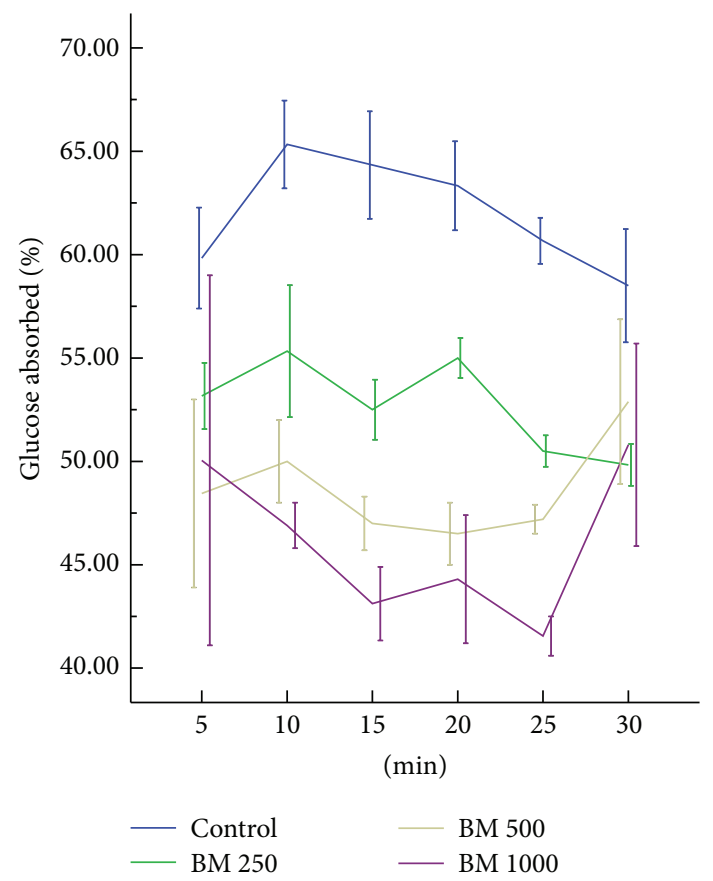

Figure 6: Effects of ethanol extract of Butea monosperma (BM) on intestinal glucose absorption in type 2 diabetic rats. Rats were fasted for $36 \mathrm{~h}$ and the intestine was perfused with glucose $(54 \mathrm{~g} / \mathrm{L})$ with or without ethanol extract of BM $(5 \mathrm{mg} / \mathrm{mL}, 10 \mathrm{mg} / \mathrm{mL}$, and $20 \mathrm{mg} / \mathrm{mL}$; each subject received $15 \mathrm{~mL}$ of perfusion). Values are means and standard deviations represented by vertical bars $(n=9)$. Mean values marked with an asterisk $(*)$ were significantly different from those of respective control rats $(P<0.05)$ (derived from repeated measures ANOVA and adjusted using Bonferroni correction).

TABLE 1: Effect of ethanolic extract of BM on insulin secretion from isolated rat islets.

\begin{tabular}{lcc}
\hline \multirow{2}{*}{ Group } & \multicolumn{2}{c}{ Insulin secretion (ng/mg islet protein) } \\
& Glucose: $3 \mathrm{mM}$ & Glucose: $11 \mathrm{mM}$ \\
\hline Control & $2.99(2.65-4.27)$ & $5.41(4.91-9.27)^{*}$ \\
BM $20 \mu \mathrm{g} / \mathrm{mL}$ & $2.65(2.23-3.71)$ & $5.19(4.41-8.72)$ \\
BM $40 \mu \mathrm{g} / \mathrm{mL}$ & $3.45(2.67-3.99)$ & $5.31(4.18-7.67)$ \\
BM $80 \mu \mathrm{g} / \mathrm{mL}$ & $5.28(3.87-6.09)^{*}$ & $7.84(6.98-9.54)^{*}$ \\
Glibenclamide $(10 \mu \mathrm{g} / \mathrm{L})$ & $5.89(4.34-6.95)^{*}$ & $8.92(7.67-9.86)^{*}$ \\
\hline
\end{tabular}

Isolated rat islets were incubated for 60 min with ethanol extract BM $(10,20$, and $30 \mathrm{mg} / \mathrm{mL}$ ) in the presence of 3 or $11 \mathrm{mM}$ glucose. Data are presented as median (range), $n=5$. Mann-Whitney $U$-test was used to evaluate statistical significance. ${ }^{*} P<0.05$ compared with control $(3 \mathrm{mM}$ glucose without extract).

3.8. Effect of B. monosperma Powder on In Vitro Glucose Dialysis Retardation Index (GDRI). B. monosperma powder did not significantly reduce the amount of glucose present in the dialysate compared to the control group (Table 2).

3.9. Effect of B. monosperma Powder on In Vitro Glucose Adsorption Capacity. B. monosperma powder failed to show 


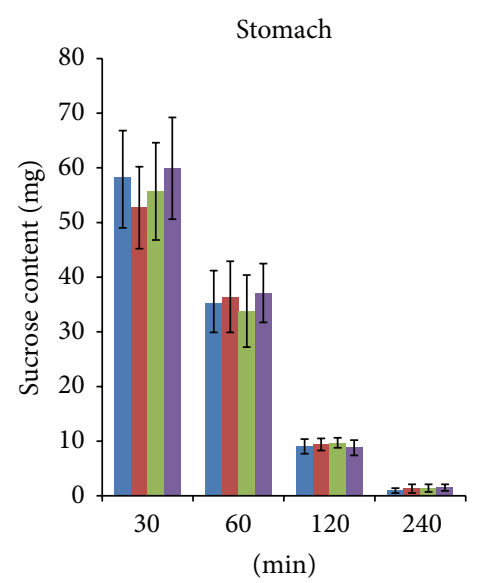

(a)

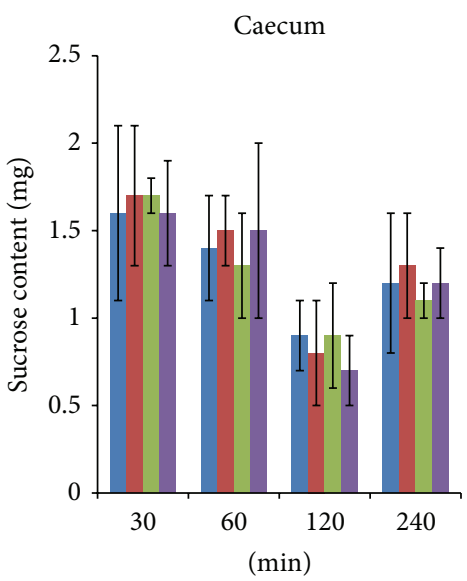

(d)

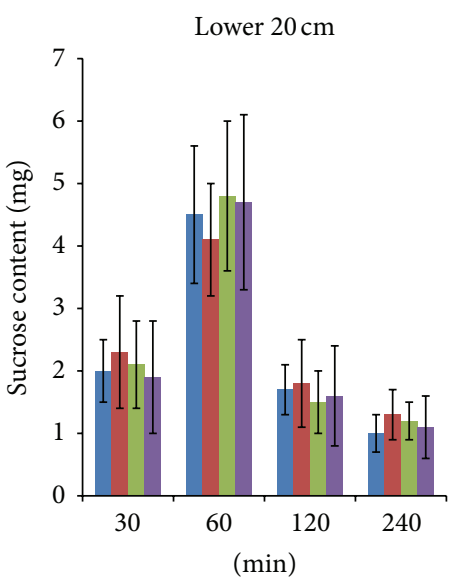

(b)

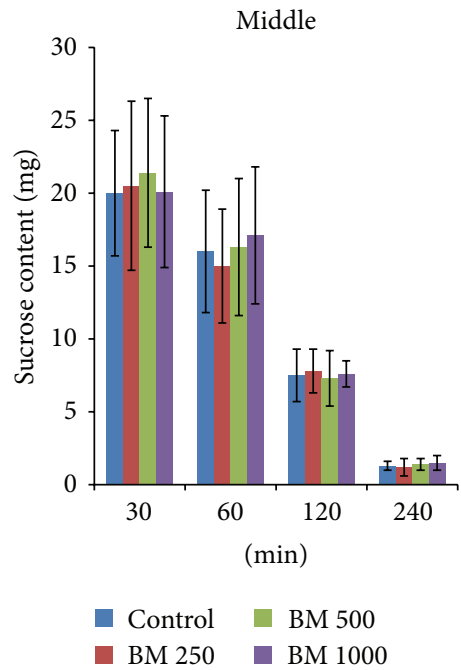

(e)

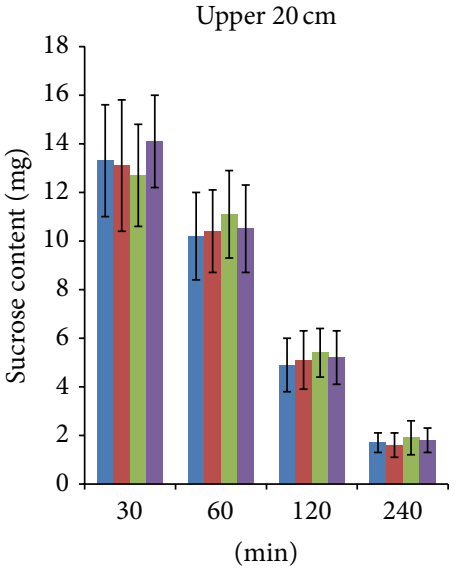

(c)

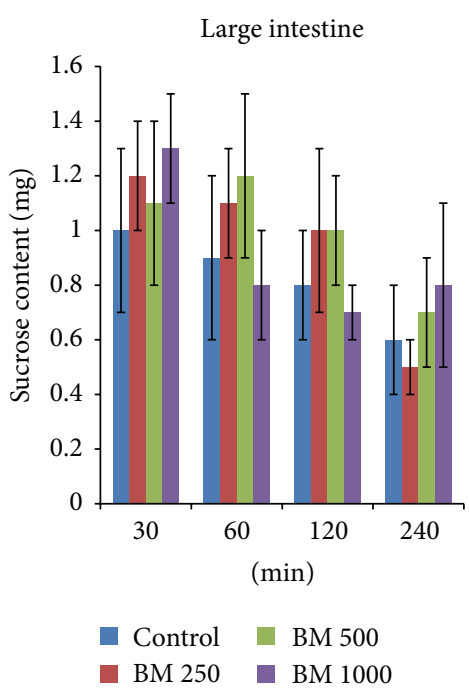

(f)

FIGURE 7: Effects of ethanol extract of Butea monosperma (BM) on gastrointestinal sucrose content after oral sucrose loading in type 2 diabetic rats. Rats were fasted for $20 \mathrm{~h}$ before the oral administration of a sucrose solution $(2.5 \mathrm{~g} / \mathrm{kg}$ body weight $)$ with or without ethanol extract of $\mathrm{BM}(250 \mathrm{mg} / \mathrm{kg}, 500 \mathrm{mg} / \mathrm{kg}$, and $1000 \mathrm{mg} / \mathrm{kg}$ body weight). Values are means and standard deviations represented by vertical bars $(n=8)$. Mean values marked with an asterisk $(*)$ were significantly different from those of control rats $(P<0.05)$ (derived from repeated measures ANOVA and adjusted using Bonferroni correction).

high capacity of glucose adsorption in the presence of different levels of glucose in the solution (Table 3).

\subsection{Effect of B. monosperma Powder on $\alpha$-Amylase Activity.} No effect of $B$. monosperma powder on starch digestibility was found by the alteration in the glucose concentration in the dialysate with time. There was no significant change, compared to control, in the glucose content at $10 \mathrm{~min}$ to $120 \mathrm{~min}$ (Table 4).

\section{Discussion}

Our study incorporates a wide range of methods to fully understand the possible underlying mechanism of antidiabetic action of B. monosperma. Preliminary studies involving determination of FBG, GTT, chronic blood glucose, and blood glucose after sucrose load, and all showed a marked, dose-dependent decline in blood glucose level on B. monosperma administration. These findings corroborated with previous studies on B. monosperma claiming antihyperglycemic activity [13-16]. Improved background glucose control hinders progression of diabetic macro- and microvascular diseases $[32,33]$. Acute hyperglycemia is known to cause pseudohypoxia. Effects of pseudohypoxia on neuronal and renal functions are mediated by a cascade of imbalances in lipid metabolism, increased production of superoxide ions, and increased nitric oxide formation, all of which are undesirable [34].

Insulin resistance as found in type 2 diabetic patients often results in various of pathological states, including, dyslipidemia, increased activity of endogenous procoagulants, endothelial dysfunction, changes in hemodynamic 


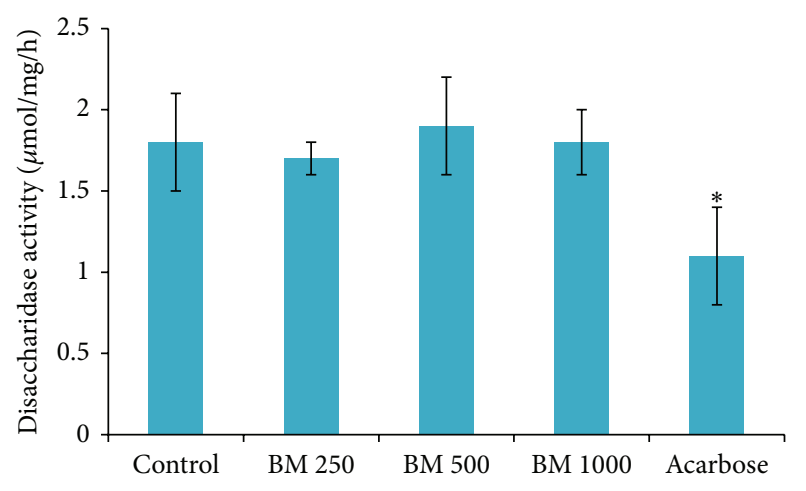

(a)

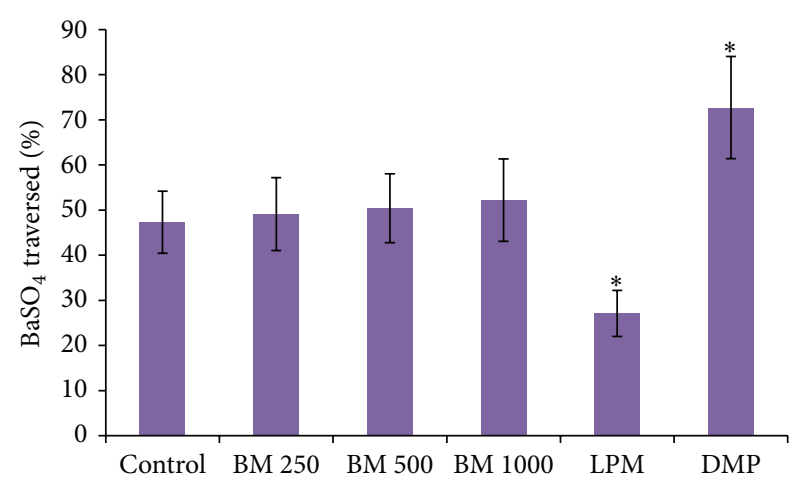

(b)

FIGURE 8: Effects of ethanol extract of Butea monosperma (BM) on (a) intestinal disaccharidase activity and (b) gastrointestinal motility (by $\mathrm{BaSO}_{4}$ traversed) in type 2 diabetic rats. Rats were fasted for $20 \mathrm{~h}$ before the oral administration of ethanol extract of $\mathrm{BM}(250 \mathrm{mg} / \mathrm{kg}$, $500 \mathrm{mg} / \mathrm{kg}$, and $1000 \mathrm{mg} / \mathrm{kg}$ body weight). Enzyme activity was determined and $\mathrm{BaSO}_{4}$ was administered at 60 min. Motility was measured over the following $15 \mathrm{~min}$. Acarbose $(200 \mathrm{mg} / \mathrm{Kg}$ ) and Loperamide (LPM) $5 \mathrm{mg} / \mathrm{Kg}$ ) and Domperidone (DMP) (10 mg/Kg) were used as reference controls for disaccharidase activity test and gastrointestinal motility test respectively. Values are means and standard deviations represented by vertical bars $(n=12)$. Mean values marked with an asterisk $(*)$ were significantly different from those of diabetic control rats $(P<0.05)$ (derived from repeated measures ANOVA and adjusted using Bonferroni correction).

TABLE 2: Retarding effect of insoluble fibre of BM on the glucose movement (glucose dialysis retardation index).

\begin{tabular}{|c|c|c|c|c|}
\hline \multirow[b]{2}{*}{ Treatment } & \multicolumn{2}{|c|}{ Dialysis for $30 \mathrm{~min}$} & \multicolumn{2}{|c|}{ Dialysis for $60 \mathrm{~min}$} \\
\hline & $\begin{array}{l}\text { Glucose in dialysate } \\
(\mathrm{mmol} / \mathrm{L})\end{array}$ & $\begin{array}{c}\text { Glucose dialysis } \\
\text { retardation index (\%) }\end{array}$ & $\begin{array}{l}\text { Glucose in dialysate } \\
(\mathrm{mmol} / \mathrm{L})\end{array}$ & $\begin{array}{c}\text { Glucose dialysis } \\
\text { retardation index (\%) }\end{array}$ \\
\hline BM $250 \mathrm{mg}$ & $0.93 \pm 0.23$ & 21.85 & $1.55 \pm 0.31$ & 9.36 \\
\hline BM $500 \mathrm{mg}$ & $0.83 \pm 0.33$ & 30.25 & $1.42 \pm 0.29$ & 16.96 \\
\hline BM $1000 \mathrm{mg}$ & $0.80 \pm 0.12$ & 32.77 & $1.39 \pm 0.42$ & 18.71 \\
\hline CMC $1000 \mathrm{mg}$ & $0.62 \pm 0.11^{*}$ & 42.86 & $0.83 \pm 0.07^{*}$ & 51.46 \\
\hline Control & $1.19 \pm 0.21$ & 0 & $1.71 \pm 0.14$ & 0 \\
\hline
\end{tabular}

Data are presented as mean $\pm \operatorname{SEM}(n=7)$. Glucose dialysis retardation index $=$ control $(100 \%)-$ fibre (\% of control value). Mean values marked with an asterisk (*) were significantly different from those of respective control groups $(P<0.05)$ (derived from repeated measures ANOVA and adjusted using Bonferroni correction).

status, and so forth, all of which increase the risk of cardiovascular diseases $[35,36]$. The dyslipidemic condition found concurrently with insulin resistance and type 2 diabetes is characterized by increased level of serum triglycerides (TG) and decreased serum HDL [37-39]. Type 2 diabetic individuals have a 2-4 times higher risk of cardiovascular diseases when compared to their nondiabetic counterparts. Chronic dyslipidemic state is thought to be the main factor of the increased risk [40]. On chronic study, type 2 diabetic rats treated with the $B$. monosperma showed a marked reduction in serum LDL, cholesterol, and TG level and a significant improvement in serum HDL level. Active compounds from B. monosperma therefore can be further explored to combat dyslipidemia associated with type 2 diabetes. Existing data on lipid profile of $B$. monosperma treated type 2 diabetic rats further substantiates our findings [13-16].

Other parameters observed during the chronic study were the liver, pancreas, and body weight. The food and water intake of the test animals were also monitored. Both food and water intake of $B$. monosperma treated type 2 diabetic rats decreased. This might be taken as a preliminary indication of improvement of their diabetic condition, as type 2 diabetic rats typically experience both polydipsia and polyphagia [41]. Changes in body weight and weight of the liver were insignificant throughout the test groups. Weight of the pancreas, however, significantly increased. Glibenclamide and its analogues are known to be capable of increasing the beta cell mass [42] and its proliferation in pancreatic islets [43]. However, our observation regarding increased pancreatic mass is still too preliminary to draw any conclusion with.

Several investigators have elucidated ability of complex carbohydrate, high molecular weight, and viscous, soluble dietary fibers, to retard glucose absorption [44-46]. Due to its high viscosity and fibre binding ability, dietary fibers, at times, proves to significantly retard absorption [44]. Dietary fibers are capable of significantly reducing the transit time in GI tract of ingested food [47]. Reduced transit time results in shorter period available for the carbohydrates in the meal to be digested and absorbed [48]. It is therefore 


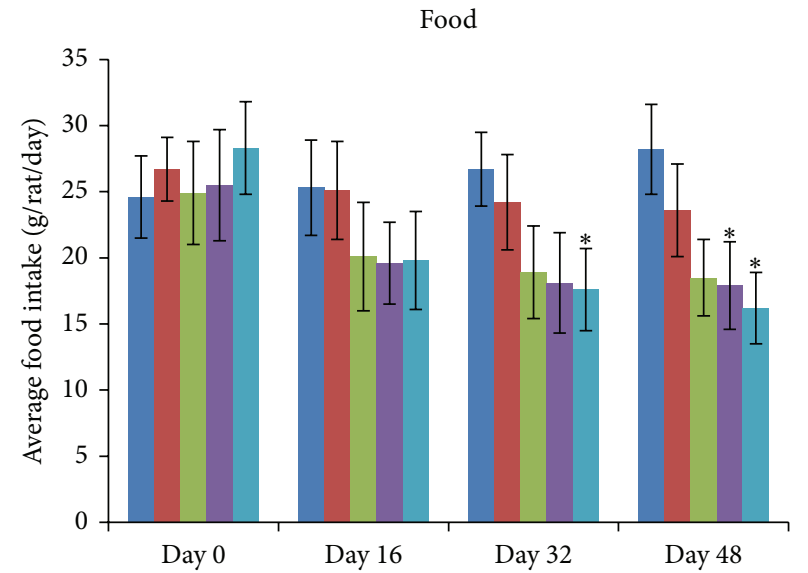

(a)

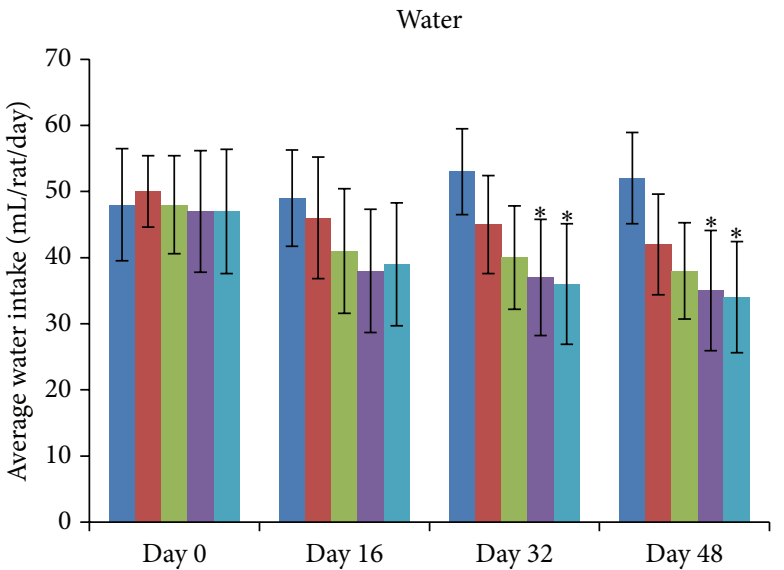

(b)

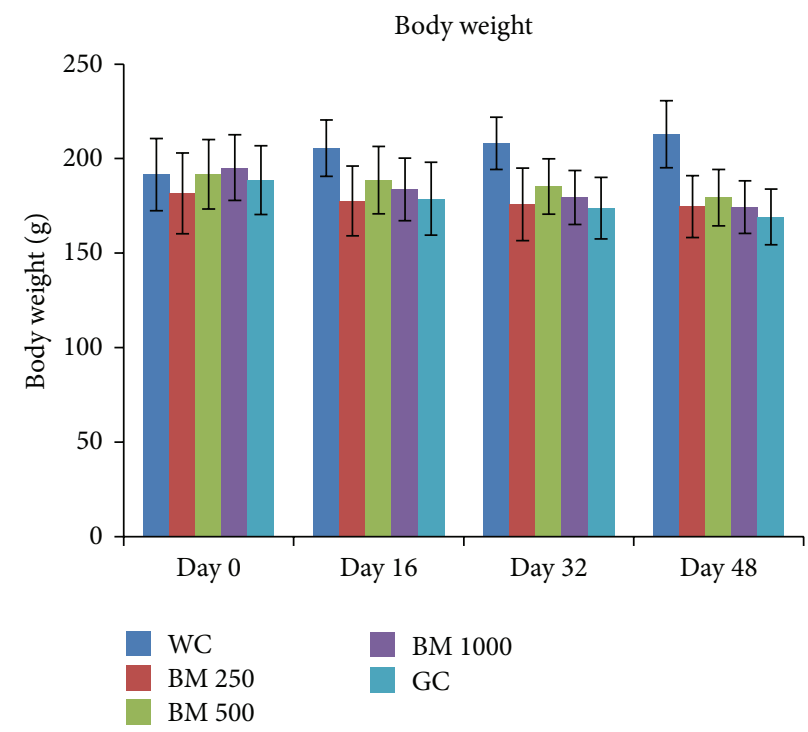

(c)

FIGURE 9: Effects of ethanol extract of Butea monosperma (BM) on body weight, average food intake, and average water intake in type 2 diabetic rats after 48 days of feeding. Values are means and standard deviations represented by vertical bars $(n=10)$. Fasted rats were given ethanol extract of BM $(250 \mathrm{mg} / \mathrm{kg}, 500 \mathrm{mg} / \mathrm{kg}$, and $1000 \mathrm{mg} / \mathrm{kg}$ body weight) or Glibenclamide (GC) $(0.5 \mathrm{mg} / \mathrm{Kg})$ by oral administration for a period of 48 days. Mean values marked with an asterisk $(*)$ were significantly different from those of respective control rats (Water control, WC) $(P<0.05)$ (derived from repeated measures ANOVA and adjusted using Bonferroni correction).

TABLE 3: Glucose adsorption capacity of insoluble fibre of BM in different concentrations of glucose.

\begin{tabular}{lccccc}
\hline Treatment & & \multicolumn{3}{c}{ Glucose bound $(\mathrm{mmol} / \mathrm{g})$} & \\
& $5 \mathrm{mmol} / \mathrm{L}$ & $10 \mathrm{mmol} / \mathrm{L}$ & $50 \mathrm{mmol} / \mathrm{L}$ & $100 \mathrm{mmol} / \mathrm{L}$ & $200 \mathrm{mmol} / \mathrm{L}$ \\
\hline BM $250 \mathrm{mg}$ & $0.01 \pm 0.01^{\mathrm{a}}$ & $0.26 \pm 0.05^{\mathrm{a}}$ & $2.15 \pm 0.51^{\mathrm{a}}$ & $5.71 \pm 1.01^{\mathrm{a}}$ & $8.39 \pm 3.81^{\mathrm{a}}$ \\
BM $500 \mathrm{mg}$ & $0.01 \pm 0.01^{\mathrm{a}}$ & $0.71 \pm 0.13^{\mathrm{a}}$ & $2.41 \pm 0.87^{\mathrm{a}}$ & $5.99 \pm 1.46^{\mathrm{a}}$ & $9.10 \pm 3.91^{\mathrm{a}}$ \\
BM 1000 mg & $0.02 \pm 0.01^{\mathrm{a}}$ & $0.95 \pm 0.20^{\mathrm{a}}$ & $2.89 \pm 0.99^{\mathrm{a}}$ & $6.27 \pm 2.02^{\mathrm{a}}$ & $9.87 \pm 4.07^{\mathrm{a}}$ \\
CMC 1000 mg & $0.08 \pm 0.01^{\mathrm{b}}$ & $2.71 \pm 0.45^{\mathrm{b}}$ & $9.32 \pm 2.09^{\mathrm{b}}$ & $17.81 \pm 3.78^{\mathrm{b}}$ & $30.97 \pm 6.88^{\mathrm{b}}$ \\
\hline
\end{tabular}

Data are presented as mean $\pm \operatorname{SEM}(n=4)$. Data represent the millimoles of glucose bound by each gram of the BM powdert at different glucose concentrations $(5-200 \mathrm{mmol} / \mathrm{L})$. Glucose bound $=($ glucose concentration of original solution - glucose concentration when the adsorption reached equilibrium $) \times$ volume of solution $\div$ weight of dietary fibre. Mean values in the same column marked with different letters were significantly different $(P<0.05)($ derived from repeated measures ANOVA and adjusted using Bonferroni correction). 


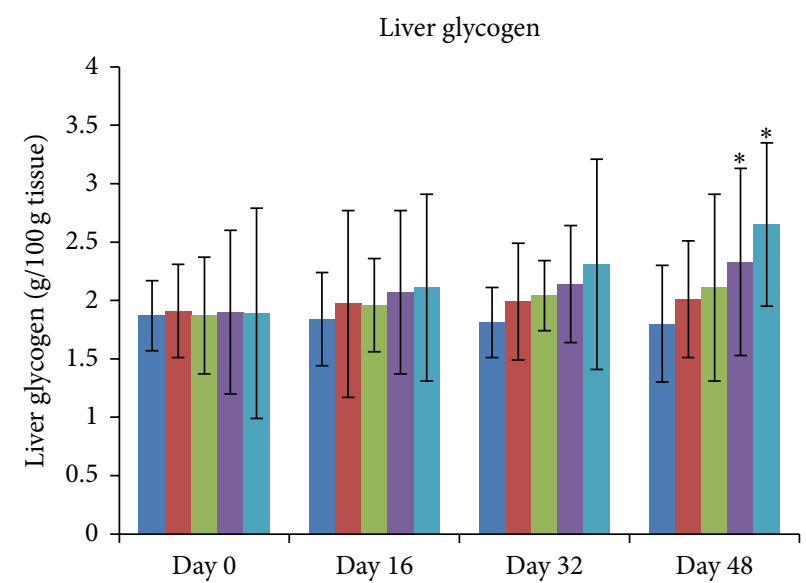

(a)

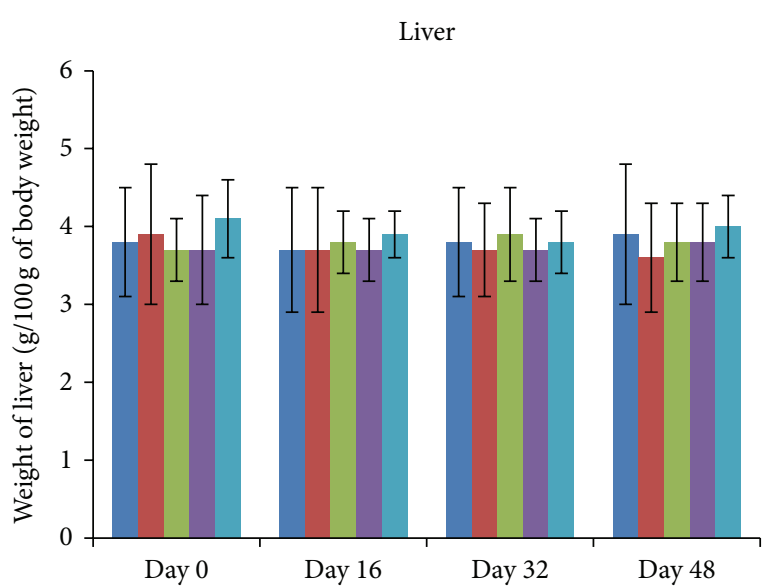

(b)

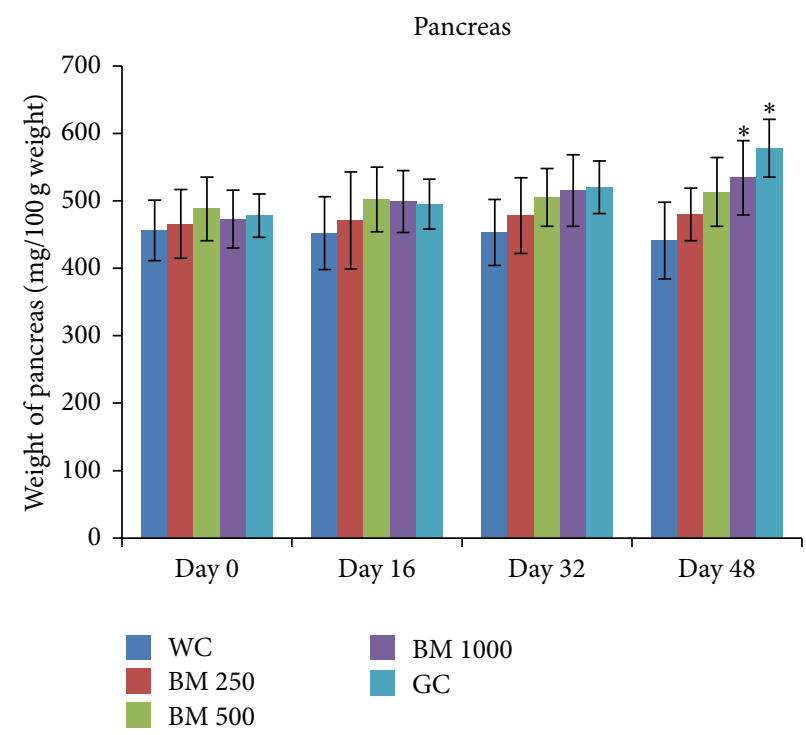

(c)

FIGURE 10: Effects of ethanol extract of Butea monosperma (BM) on liver glycogen, liver weight, and pancreas weight in type 2 diabetic rats after 48 days of feeding. Values are means and standard deviations represented by vertical bars $(n=10)$. Fasted rats were given ethanol extract of BM $(250 \mathrm{mg} / \mathrm{kg}, 500 \mathrm{mg} / \mathrm{kg}$, and $1000 \mathrm{mg} / \mathrm{kg}$ body weight $)$ or Glibenclamide (GC) $(0.5 \mathrm{mg} / \mathrm{Kg})$ by oral administration for a period of 48 days. Mean values marked with an asterisk $(*)$ were significantly different from those of respective control rats (Water control, WC) $(P<0.05)$ (derived from repeated measures ANOVA and adjusted using Bonferroni correction).

TABLE 4: Effect of insoluble fibre of BM on starch digestibility.

\begin{tabular}{lcccc}
\hline \multirow{2}{*}{ Treatment } & \multicolumn{3}{c}{ Glucose in dialysate $(\mu \mathrm{mol} / \mathrm{L})$} \\
& $10 \mathrm{~min}$ & $30 \mathrm{~min}$ & $60 \mathrm{~min}$ & $120 \mathrm{~min}$ \\
\hline BM $250 \mathrm{mg}$ & $1.89 \pm 0.11$ & $3.99 \pm 0.17$ & $11.78 \pm 1.55$ & $19.91 \pm 4.73$ \\
BM $500 \mathrm{mg}$ & $1.86 \pm 0.15$ & $3.45 \pm 0.30$ & $12.61 \pm 2.81$ & $19.78 \pm 6.11$ \\
BM 1000 mg & $1.91 \pm 0.19$ & $3.48 \pm 0.39$ & $16.09 \pm 2.31^{*}$ & $20.88 \pm 5.12$ \\
CMC 1000 mg & $1.91 \pm 0.21$ & $4.94 \pm 0.34^{*}$ & $12.56 \pm 1.23$ & $26.57 \pm 5.34^{*}$ \\
Control & $1.52 \pm 0.06$ & $3.87 \pm 0.12$ & $19.51 \pm 3.73$ \\
\hline
\end{tabular}

Data are presented as mean \pm SEM $(n=4)$. Values represent the glucose concentration $(\mu$ mol $)$ in dialysate. Mean values marked with an asterisk $\left({ }^{*}\right)$ were significantly different from those of respective control groups $(P<0.05)$ (derived from repeated measures ANOVA and adjusted using Bonferroni correction). 


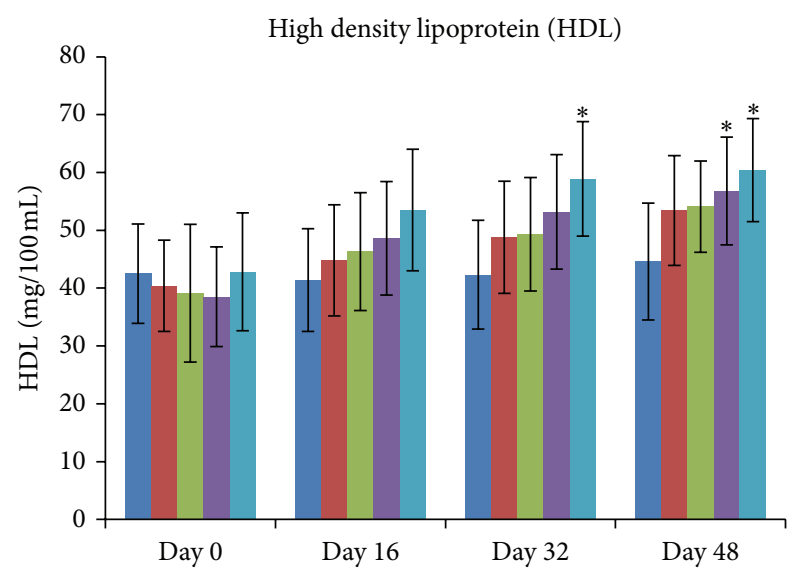

(a)

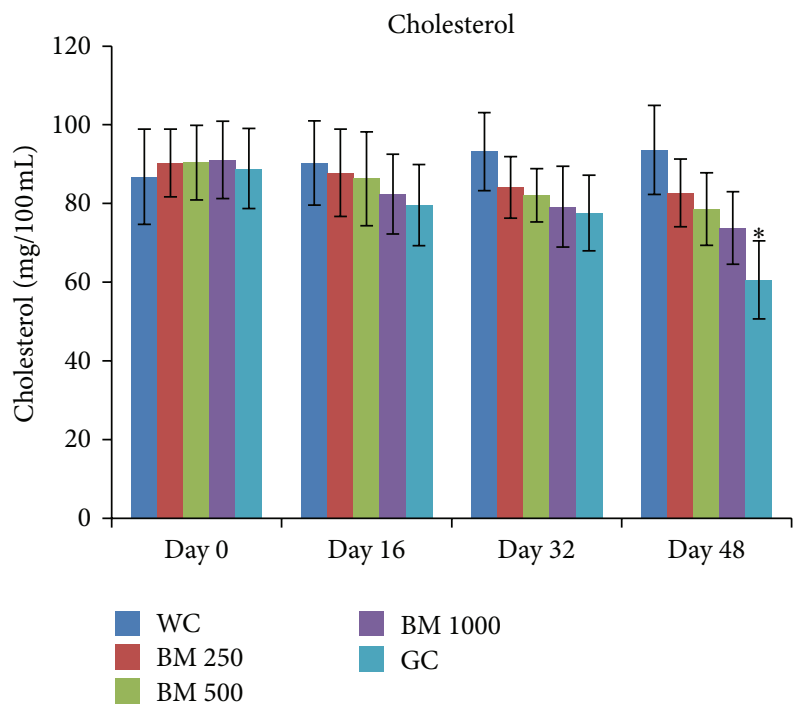

(c)

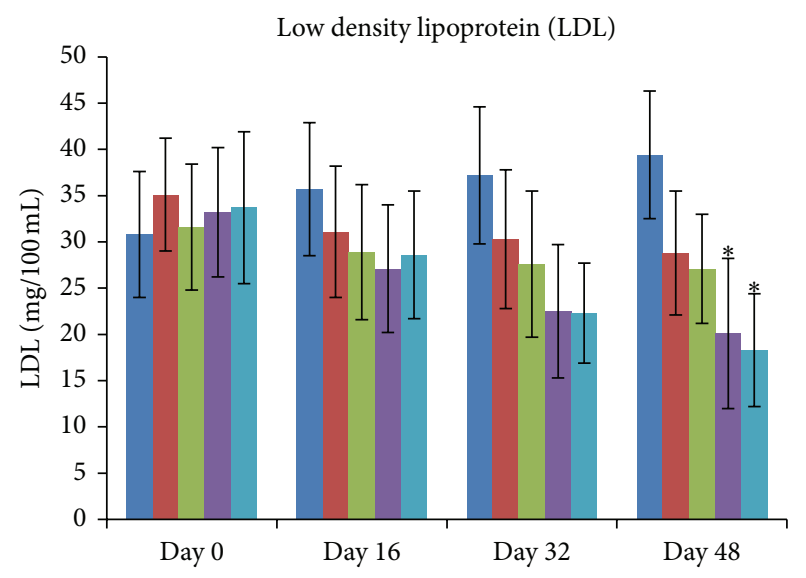

(b)

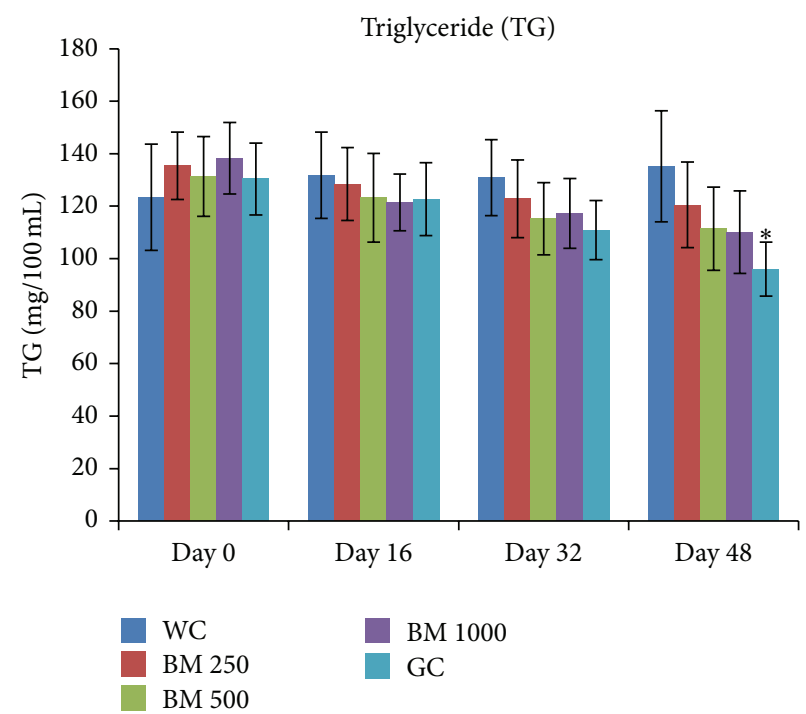

(d)

FIGURE 11: Effects of ethanol extract of Butea monosperma (BM) on serum lipid profile (TG, Cholesterol, HDL, and LDL) in type 2 diabetic rats after 48 days of feeding. Values are means and standard deviations represented by vertical bars $(n=10)$. Fasted rats were given ethanol extract of BM $(250 \mathrm{mg} / \mathrm{kg}, 500 \mathrm{mg} / \mathrm{kg}$, and $1000 \mathrm{mg} / \mathrm{kg}$ body weight $)$ or Glibenclamide (GC) $(0.5 \mathrm{mg} / \mathrm{Kg})$ by oral administration for a period of 48 days. Mean values marked with an asterisk (*) were significantly different from those of respective control rats (Water control, WC) $(P<0.05)$ (derived from repeated measures ANOVA and adjusted using Bonferroni correction).

a valuable mode of preventing postprandial hyperglycemia but has not been extensively studies till to-date. In our studies, however, both the in vitro assays, meant to study, B. monosperma fibre-glucose binding yielded no significant results. This was further confirmed by carrying out a set of two in vivo assays, "perfusion of rat intestine" and "six segments study on isolated rat intestine." These two assays, in conjunction, reconfirm our observation in the in vitro tests. Additionally, GI motility test showed no significant change in this parameter. Consequently, the possibility of hindered sugar absorption, being a possible mechanism of activity of B. monosperma, can be ruled out.

Reduced carbohydrate digestion is highly effective in controlling postprandial glucose in diabetic patients. Acarbose, an $\alpha$-glucosidase inhibitor specifically reduces postprandial hyperglycemia. Acarbose treatment resulted in a $36 \%$ risk reduction of progression to diabetes [49], 34\% risk reduction in the development of new cases of hypertension, and $49 \%$ risk reduction in cardiovascular events [50]. In vitro enzyme activity assays confirmed the lack of significant inhibitory activity of $B$. monosperma on $\alpha$-amylase and extracted intestinal disaccharidases. Hence, B. monosperma probably does not inhibit digestion of starch or other edible disaccharides.

Intensive insulin therapy is invaluable in treatment of type 1 diabetes. Diabetic patients affected by type 2 diabetes on the other hand are usually treated with insulin sensitizers to enhance body's response to the endogenously secreted insulin. Studies, however, have shown that type 2 diabetic patients exposed to higher than normal insulin level experience additional insulin secretion, normalization of hepatic glucose utilization, and partial reversal of the postbinding defect in peripheral insulin action [51]. It is 
widely acknowledged that abnormality in insulin secretion and action plays significant role in development of type 2 diabetes. "Insulin secretory dysfunction in type 2 diabetes is both qualitative and quantitative," as stated by Pratley et al. [52]. Type 2 diabetic patients also experience marked reduction in peripheral glucose utilization [53].

The novel and most remarkable findings of our study were elevation of blood insulin level in type 2 diabetic rats, stimulated insulin release from isolated rat islets, and increased deposition of glycogen in rat liver. Active compound or an amalgam active compounds of in B. monosperma have strong potential in treating both types 1 and 2 diabetes by enhancing quality and quantity of insulin secreted and by enhancing hepatic glucose utilization. A notable limitation of the current study was a lack of histological analysis, which could have corelated the enhanced insulin secretion to improved beta-cell morphology. We are currently working on isolating potential bioactive compounds from $B$. monosperma and shed light on receptor level mechanism behind its antidiabetic activity.

\section{Conclusions}

A near exhaustive study was carried out on ethanolic extract of $B$. monosperma, where we made an attempt to explore almost every possible dimension through which it might impart its previously claimed antihyperglycemic activity. Our present study rules out possibilities of retarded glucose absorption or inhibition of enzyme activities by $B$. monosperma. A triad of plasma insulin assay stimulated insulin secretion from isolated rat islets and liver glycogen level provides us with sufficient preliminary evidences, which enables us to attribute the antihyperglycemic action of $B$. monosperma to enhanced insulin secretion and enhanced hepatic glycogen formation.

\section{Conflict of Interests}

The authors declare that there is no conflict of interests regarding the publication of this paper.

\section{Acknowledgments}

The authors would like to extend their sincerest gratitude to Junaida Khaleque, Mr. Pandey, Mr. Sadrul, Mr. Ratib Mortuza Ali, and Ms. Tonima Tasnim Ananna for their remarkable support in the scientific work. The study was supported by a generous graduate research grant from North South University.

\section{References}

[1] C. S. Cockram, "The epidemiology of diabetes mellitus in the Asia-Pacific region," Hong Kong Medical Journal, vol. 6, no. 1, pp. 43-52, 2000.

[2] EURODIAB ACE Study Group, "Variation and trends in incidence of childhood diabetes in Europe," The Lancet, vol. 355, no. 9207, pp. 873-876, 2000.
[3] P. Aschner, "Diabetes trends in Latin America," Diabetes/ Metabolism Research and Reviews, vol. 18, no. 3, pp. S27-S31, 2002.

[4] A. Fagot-Campagna, D. J. Pettitt, M. M. Engelgau et al., “Type 2 diabetes among North American children and adolescents: an epidemiologic review and a public health perspective," Journal of Pediatrics, vol. 136, no. 5, pp. 664-672, 2000.

[5] E. S. Huang, A. Basu, M. O’Grady, and J. C. Capretta, "Projecting the future diabetes population size and related costs for the U.S," Diabetes Care, vol. 32, no. 12, pp. 2225-2229, 2009.

[6] D. Yach, D. Stuckler, and K. D. Brownell, "Epidemiologic and economic consequences of the global epidemics of obesity and diabetes," World, vol. 5, no. 9.4, p. 8, 2006.

[7] F. B. Hu, "Globalization of diabetes: the role of diet, lifestyle, and genes," Diabetes Care, vol. 34, no. 6, pp. 1249-1257, 2011.

[8] R. C. Turner, C. A. Cull, V. Frighi, and R. R. Holman, "Glycemic control with diet, sulfonylurea, metformin, or insulin in patients with type 2 diabetes mellitus. Progressive requirement for multiple therapies (UKPDS 49)," Journal of the American Medical Association, vol. 281, no. 21, pp. 2005-2012, 1999.

[9] A. J. Krentz and C. J. Bailey, "Oral antidiabetic agents: current role in type 2 diabetes mellitus," Drugs, vol. 65, no. 3, pp. 385411, 2005.

[10] H. King, R. E. Aubert, and W. H. Herman, "Global burden of diabetes, 1995-2025: prevalence, numerical estimates, and projections," Diabetes Care, vol. 21, no. 9, pp. 1414-1431, 1998.

[11] E. Ernst, "Prevalence of use of complementary/alternative medicine: a systematic review," Bulletin of the World Health Organization, vol. 78, no. 2, pp. 252-257, 2000.

[12] E. Ernst, "The role of complementary and alternative medicine," British Medical Journal, vol. 321, no. 7269, pp. 1133-1135, 2000.

[13] R. Somani, S. Kasture, and A. K. Singhai, "Antidiabetic potential of Butea monosperma in rats," Fitoterapia, vol. 77, no. 2, pp. 8690, 2006.

[14] J. H. Bavarva and A. V. R. L. Narasimhacharya, "Preliminary study on antihyperglycemic and antihyperlipaemic effects of Butea monosperma in NIDDM rats," Fitoterapia, vol. 79, no. 5, pp. 328-331, 2008.

[15] N. Sharma and V. Garg, "Antihyperglycemic and antioxidative potential of hydroalcoholic extract of butea monosperma lam flowers in alloxan-induced diabetic mice," Indian Journal of Experimental Biology, vol. 47, no. 7, pp. 571-576, 2009.

[16] S. Panda, M. Jafri, A. Kar, and B. K. Meheta, "Thyroid inhibitory, antiperoxidative and hypoglycemic effects of stigmasterol isolated from Butea monosperma," Fitoterapia, vol. 80, no. 2, pp. 123-126, 2009.

[17] A. Sehrawat and S. Sultana, "Chemoprevention by Butea monosperma of hepatic carcinogenesis and oxidative damage in male wistar rats," Asian Pacific Journal of Cancer Prevention, vol. 7, no. 1, pp. 140-148, 2006.

[18] N. Sharma and V. Garg, "Antidiabetic and antioxidant potential of ethanolic extract of Butea monosperma leaves in alloxaninduced diabetic mice," Indian Journal of Biochemistry and Biophysics, vol. 46, no. 1, pp. 99-105, 2009.

[19] A. M. Gallagher, P. R. Flatt, G. Duffy, and Y. H. A. Abdel-Wahab, "The effects of traditional antidiabetic plants on in vitro glucose diffusion," Nutrition Research, vol. 23, no. 3, pp. 413-424, 2003.

[20] K. Bayne, "Revised guide for the care and use of laboratory animals available. American physiological society," The Physiologist, vol. 39, no. 4, pp. 199-211, 1996. 
[21] S. Lenzen, "The mechanisms of alloxan- and streptozotocininduced diabetes," Diabetologia, vol. 51, no. 2, pp. 216-226, 2008.

[22] M. Moniruzzaman, B. Rokeya, S. Ahmed, A. Bhowmik, I. Khalil, and S. H. Gan, "In vitro antioxidant effects of Aloe barbadensis Miller extracts and the potential role of these extracts as antidiabetic and antilipidemic agents on streptozotocininduced type 2 diabetic model rats," Molecules, vol. 17, no. 11, pp. 12851-12867, 2012.

[23] P. Trinder, "Enzymatic Colorimetric method for estimation of Glucose Test (GOD-PAP method), uric acid and phosohlipids," Annals of Clinical Biochemistry, vol. 6, p. 25, 1969.

[24] S. Moskalewski, "Studies on the culture and transplantation of isolated islets of langerhans of the guinea pig," Proceedings of the Koninklijke Nederlandse Akademie van Wetenschappen C, vol. 72, no. 2, pp. 157-171, 1969.

[25] J. van der Vies, "Two methods for the determination of glycogen in liver," The Biochemical Journal, vol. 57, no. 3, pp. 410-416, 1954.

[26] J. V. Swintosky and E. Pogonowska-Wala, "The in-situ rat gut technique," Pharmacy International, vol. 3, no. 5, pp. 163-167, 1982.

[27] J. M. A. Hannan, L. Ali, B. Rokeya et al., "Soluble dietary fibre fraction of Trigonella foenum-graecum (fenugreek) seed improves glucose homeostasis in animal models of type 1 and type 2 diabetes by delaying carbohydrate digestion and absorption, and enhancing insulin action," British Journal of Nutrition, vol. 97, no. 3, pp. 514-521, 2007.

[28] Y. Goto, K. Yamada, T. Ohyama, T. Matsuo, H. Odaka, and H. Ikeda, "An $\alpha$-glucosidase inhibitor, AO-128, retards carbohydrate absorption in rats and humans," Diabetes Research and Clinical Practice, vol. 28, no. 2, pp. 81-87, 1995.

[29] T. Chatterjee, Handbook of Laboratory Mice and Rats, Jadavpur University, Kolkata, India, 1993.

[30] C.-F. Chau, Y.-L. Huang, and M.-H. Lee, "In vitro hypoglycemic effects of different insoluble fiber-rich fractions prepared from the peel of Citrus sinensis L. cv. Liucheng," Journal of Agricultural and Food Chemistry, vol. 51, no. 22, pp. 6623-6626, 2003.

[31] S. Ou, K.-C. Kwok, Y. Li, and L. Fu, "In vitro study of possible role of dietary fiber in lowering postprandial serum glucose," Journal of Agricultural and Food Chemistry, vol. 49, no. 2, pp. 1026-1029, 2001.

[32] R. Turner, "Intensive blood-glucose control with sulphonylureas or insulin compared with conventional treatment and risk of complications in patients with type 2 diabetes (UKPDS 33)," The Lancet, vol. 352, no. 9131, pp. 837-853, 1998.

[33] R. Klein, "Hyperglycemia and microvascular and macrovascular disease in diabetes," Diabetes Care, vol. 18, no. 2, pp. 258-268, 1995.

[34] J. R. Williamson, K. Chang, M. Frangos et al., "Hyperglycemic pseudohypoxia and diabetic complications," Diabetes, vol. 42, no. 6, pp. 801-813, 1993.

[35] R. W. Nesto, "Correlation between cardiovascular disease and diabetes mellitus: current concepts," The American Journal of Medicine, vol. 116, no. 5, pp. 11-22, 2004.

[36] W. A. Hsueh, C. J. Lyon, and M. J. Quiñones, "Insulin resistance and the endothelium," The American Journal of Medicine, vol. 117, no. 2, pp. 109-117, 2004.

[37] H. N. Ginsberg, "Insulin resistance and cardiovascular disease," Journal of Clinical Investigation, vol. 106, no. 4, pp. 453-458, 2000.
[38] R. D. Siegel, A. Cupples, E. J. Schaefer, and P. W. F. Wilson, "Lipoproteins, apolipoproteins, and low-density lipoprotein size among diabetics in the Framingham offspring study," Metabolism: Clinical and Experimental, vol. 45, no. 10, pp. 12671272, 1996.

[39] R. M. Krauss, "Lipids and lipoproteins in patients with type 2 diabetes," Diabetes Care, vol. 27, no. 6, pp. 1496-1504, 2004.

[40] S. M. Haffner, "Dyslipidemia management in adults with diabetes," Diabetes Care, vol. 27, p. S68, 2004.

[41] K. Kawano, T. Hirashima, S. Mori, Y. Saitoh, M. Kurosumi, and T. Natori, "Spontaneous long-term hyperglycemic rat with diabetic complications: otsuka Long-Evans Tokushima Fatty (OLETF) strain," Diabetes, vol. 41, no. 11, pp. 1422-1428, 1992.

[42] S. Schneider, P. J. Feilen, M. Schreckenberger et al., "In vitro and in vivo evaluation of novel glibenclamide derivatives as imaging agents for the non-invasive assessment of the pancreatic islet cell mass in animals and humans," Experimental and Clinical Endocrinology and Diabetes, vol. 113, no. 7, pp. 388-395, 2005.

[43] Y. Guiot, J.-B. Henquin, and J. Rahier, "Effects of glibenclamide on pancreatic $\beta$-cell proliferation in vivo," European Journal of Pharmacology, vol. 261, no. 1-2, pp. 157-161, 1994.

[44] D. J. A. Jenkins, T. M. S. Wolever, and A. R. Leeds, "Dietary fibres, fibre analogues, and glucose tolerance: importance of viscosity," British Medical Journal, vol. 1, no. 6124, pp. 1392-1394, 1978.

[45] P.-H. Groop, A. Aro, S. Stenman, and L. Groop, "Long-term effects of guar gum in subjects with non-insulin-dependent diabetes mellitus," American Journal of Clinical Nutrition, vol. 58, no. 4, pp. 513-518, 1993.

[46] C. A. Edwards, I. T. Johnson, and N. W. Read, "Do viscous polysaccharides slow absorption by inhibiting diffusion or convection?" European Journal of Clinical Nutrition, vol. 42, no. 4, pp. 307-312, 1988.

[47] D. P. Burkitt, A. R. Walker, and N. S. Painter, "Effect of dietary fibre on stools and the transit-times, and its role in the causation of disease," The Lancet, vol. 2, no. 7792, pp. 1408-1412, 1972.

[48] A. M. Holgate and N. W. Read, "Relationship between small bowel transit time and absorption of a solid meal. Influence of metoclopramide, magnesium sulfate, and lactulose," Digestive Diseases and Sciences, vol. 28, no. 9, pp. 812-819, 1983.

[49] J.-L. Chiasson, R. G. Josse, R. Gomis, M. Hanefeld, A. Karasik, and M. Laakso, "Acarbose for prevention of type 2 diabetes mellitus: the STOP-NIDDM randomised trial," The Lancet, vol. 359, no. 9323, pp. 2072-2077, 2002.

[50] J.-L. Chiasson, R. G. Josse, R. Gomis, M. Hanefeld, A. Karasik, and M. Laakso, "Acarbose treatment and the risk of cardiovascular disease and hypertension in patients with impaired glucose tolerance: the STOP-NIDDM trial," Journal of the American Medical Association, vol. 290, no. 4, pp. 486-494, 2003.

[51] W. T. Garvey, J. M. Olefsky, and J. Griffin, "The effect of insulin treatment on insulin secretion and insulin action in type II diabetes mellitus," Diabetes, vol. 34, no. 3, pp. 222-234, 1985.

[52] R. E. Pratley and C. Weyer, "The role of impaired early insulin secretion in the pathogenesis of Type II diabetes mellitus," Diabetologia, vol. 44, no. 8, pp. 929-945, 2001.

[53] R. A. DeFronzo, R. Gunnarsson, and O. Bjorkman, "Effects of insulin on peripheral and splanchnic glucose metabolism in noninsulin-dependent (type II) diabetes mellitus," Journal of Clinical Investigation, vol. 76, no. 1, pp. 149-155, 1985. 


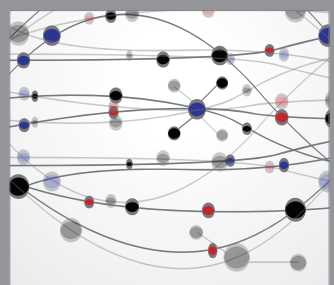

The Scientific World Journal
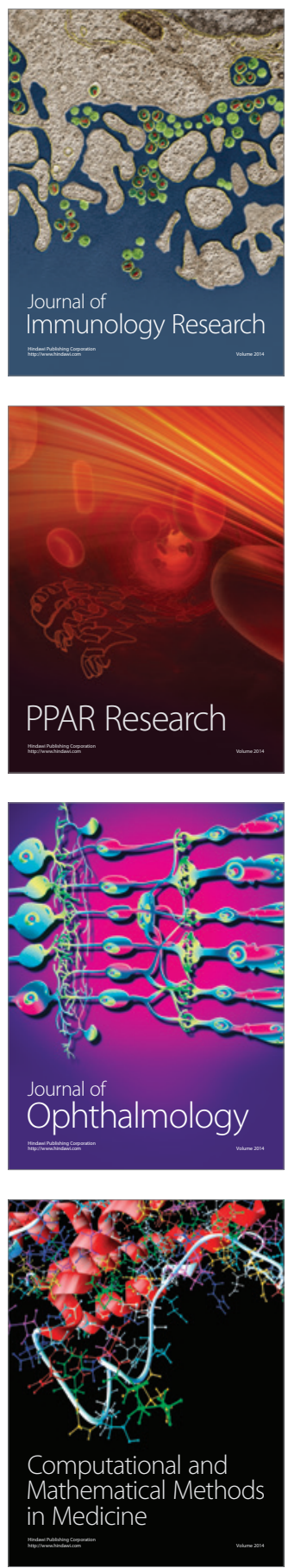

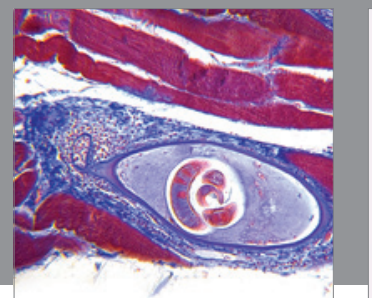

Gastroenterology

Research and Practice
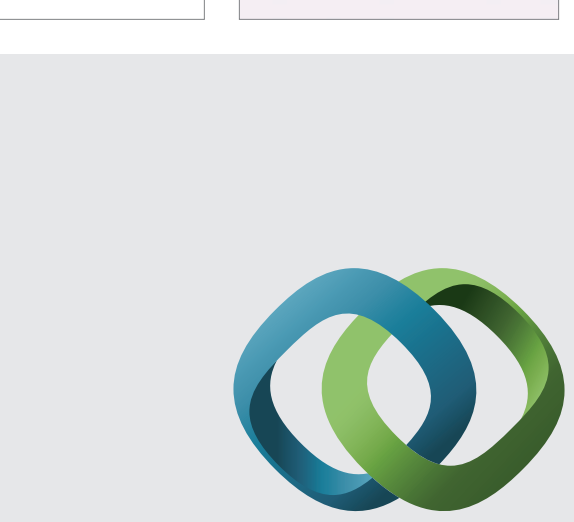

\section{Hindawi}

Submit your manuscripts at

http://www.hindawi.com
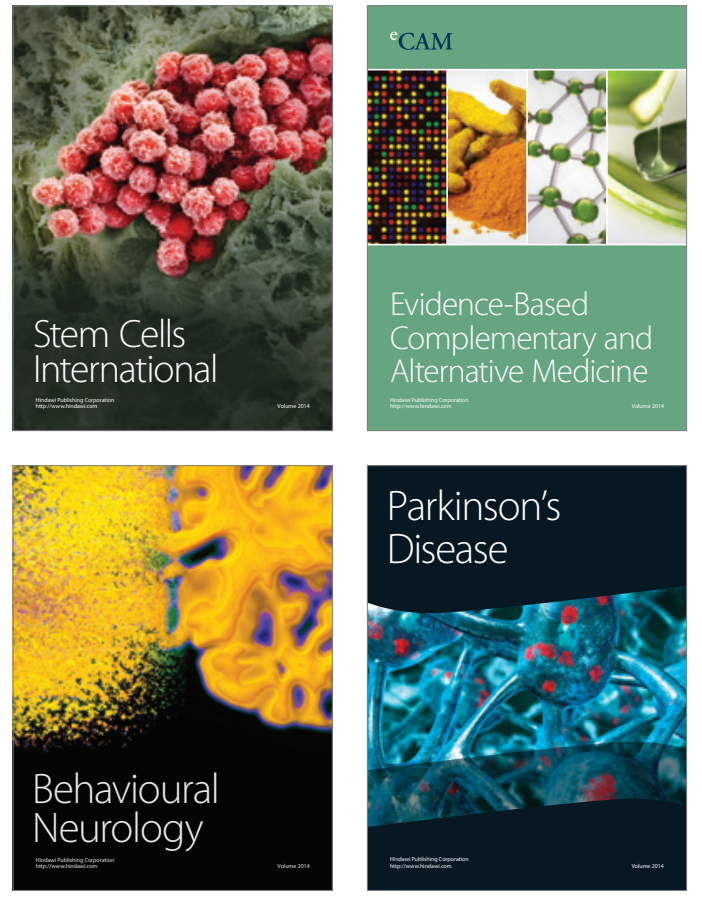
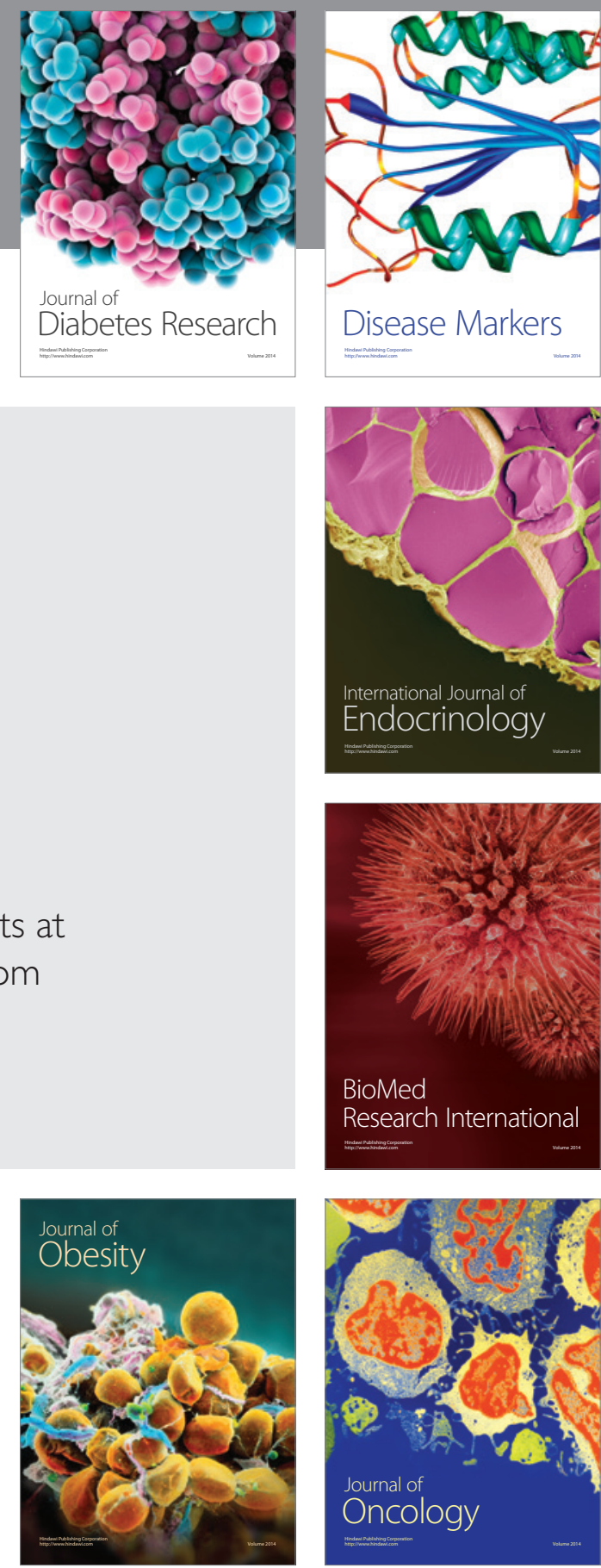

Disease Markers
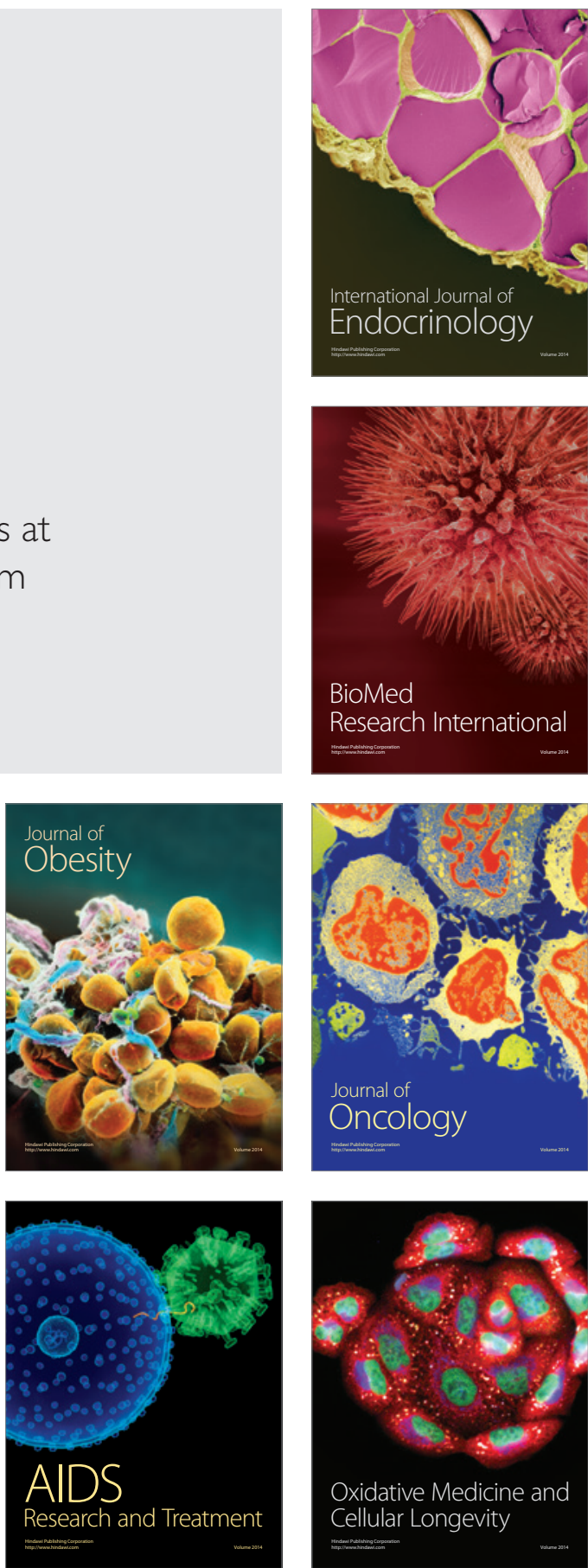